\title{
The effects of non-thermal electron beam irradiation on quality indicators of peanut butter
}

\author{
Amanda El-Rawas \\ West Virginia University
}

Follow this and additional works at: https://researchrepository.wvu.edu/etd

\section{Recommended Citation}

El-Rawas, Amanda, "The effects of non-thermal electron beam irradiation on quality indicators of peanut butter" (2010). Graduate Theses, Dissertations, and Problem Reports. 4585.

https://researchrepository.wvu.edu/etd/4585

This Thesis is protected by copyright and/or related rights. It has been brought to you by the The Research Repository @ WVU with permission from the rights-holder(s). You are free to use this Thesis in any way that is permitted by the copyright and related rights legislation that applies to your use. For other uses you must obtain permission from the rights-holder(s) directly, unless additional rights are indicated by a Creative Commons license in the record and/ or on the work itself. This Thesis has been accepted for inclusion in WVU Graduate Theses, Dissertations, and Problem Reports collection by an authorized administrator of The Research Repository @ WVU. For more information, please contact researchrepository@mail.wvu.edu. 
The Effects of Non-thermal Electron Beam Irradiation on Quality Indicators of Peanut Butter

\author{
Amanda El-Rawas \\ Thesis submitted to the \\ College of Agriculture, Natural Resources and Design \\ at West Virginia University \\ in partial fulfillment of the requirements \\ for the degree of
}

Master of Science

In

Human Nutrition and Foods

Kristen E. Matak, Ph.D., Chair

Jacek Jaczynski, Ph.D

Kimberly M. Barnes, Ph.D

Department of Animal and Nutritional Sciences

Morgantown, West Virginia

2010

Keywords: Electron beam irradiation, peanut butter, quality parameter

Copyright 2010 Amanda El-Rawas 


\section{ABSTRACT \\ The Effects of Non-thermal Electron Beam Irradiation on the Quality of Peanut Butter}

\section{Amanda El-Rawas}

Electron beam (e-beam) irradiation is an effective non-thermal processing step for the reduction of Salmonella in peanut butter. The objective of this study was to evaluate the effects of e-beam irradiation on the quality of peanut butter. Peanut butter samples were exposed to e-beam doses of 0 (control), 3.2, 7.0, or 27.7 kGy, confirmed by film dosimetry. Doses correlated with a 5and 12-log reduction of Salmonella respectively; with $27.7 \mathrm{kGy}$ representing an extreme dose. Samples were examined over a 15 -day period at $22^{\circ} \mathrm{C}$. Color analysis (L, a*, b*), spreadability, and thiobarbituric acid reactive substances test (TBARS) for lipid oxidation were measured over a two-week storage period. Fatty acid profiles were measured on days 3 and 15 and amino acid profile was measured on day-15. Protein degradation was measured on day-15 by sodium dodecyl sulfate polyacrylamide gel electrophoresis (SDS-Page). TBARS showed an increase in malondialdehyde (MDA) formation with e-beam dose $(P<0.05)$ and changes were seen over time; yet changes over time were not significant $(P>0.05)$. No changes in total saturated fatty acid content, total unsaturated fatty acid content, total monounsaturated fatty acid content, or total polyunsaturated fatty acid content were observed by dose or over time $(P>0.05)$. No changes in crude or total protein were observed; however decreases in serine, tyrosine, histidine, and arginine were observed with dose $(P<0.05)$. SDS-PAGE showed decreases in band pixel density at $27.7 \mathrm{kGy}$, indicating degradation of proteins $(P<0.05)$. Linear regression showed no changes in spreadability, measured by force $(g)$ were observed $(P>0.05)$. Significant changes in color $(P<0.05)$ were observed as e-beam dose increased. These results demonstrate e-beam irradiation when applied to peanut butter to produce significant changes in color and protein degradation. No changes were observed in total protein content, or total saturated and unsaturated fatty acid content. Future studies may include sensory evaluation and consumer acceptance studies. 


\section{DEDICATION}

I would like to dedicate this thesis to my best friend, Oussama El-Rawas, who has provided the endless support and encouragement that made its completion possible. 


\section{ACKNOWLEDGEMENTS}

I would like to thank my advisor, Dr. Kristen Matak, for her patience, encouragement, and much needed guidance through this Masters thesis. Special thanks to Sarah Beamer, Andrea Hvizdzak, and Matthew Davenport for their assistance in the lab. Thanks to my committee members, Dr. Jacak Jaczynski and Dr. Kimberly Barnes for their advice and assistance. Lastly I would like to thank Sterigenics for allowing me to use their facilities and electron beam accelerator. 


\section{TABLE OF CONTENTS}

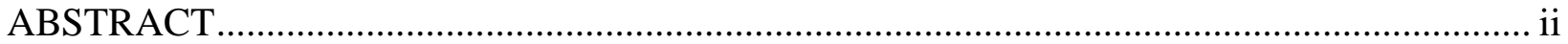

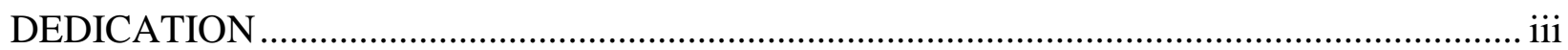

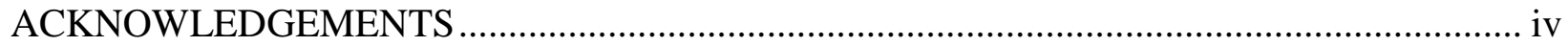

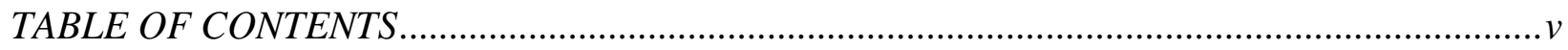

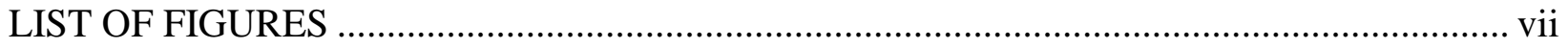

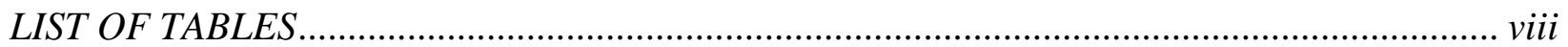

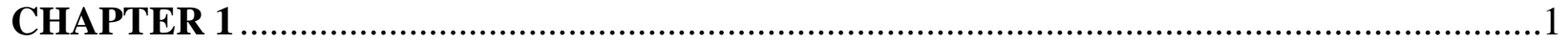

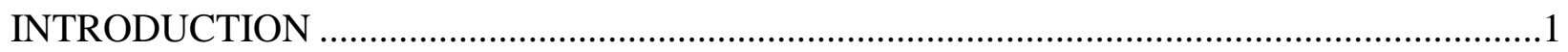

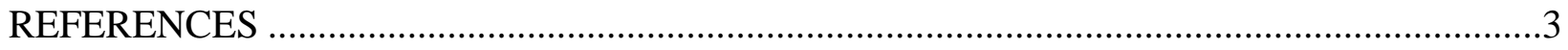

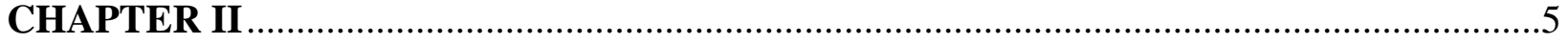

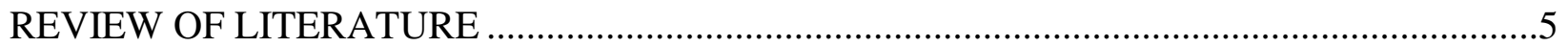

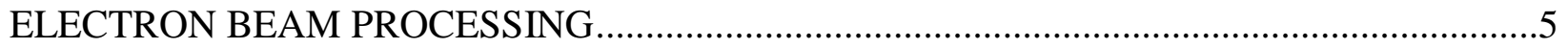

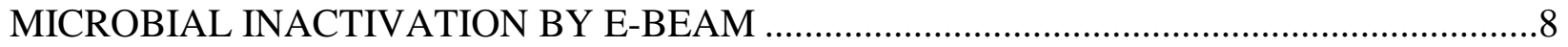

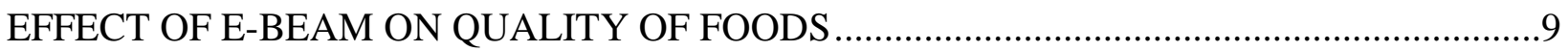

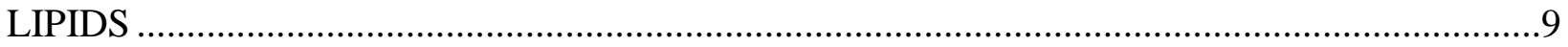

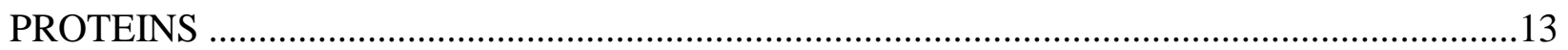

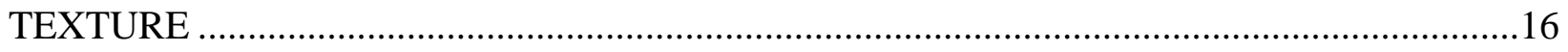

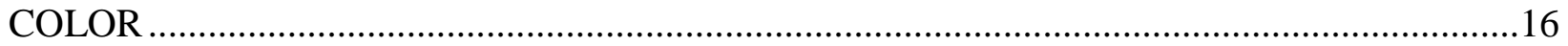

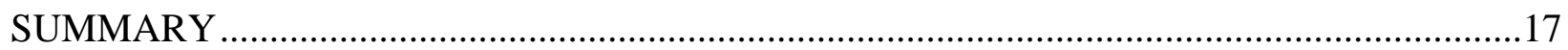

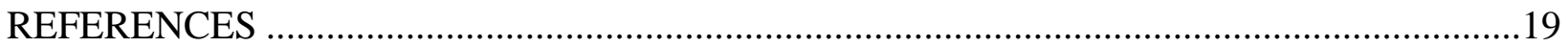


THE EFFECTS OF NON-THERMAL ELECTRON BEAM IRRADIATION ON THE

QUALITY OF PEANUT BUTTER.

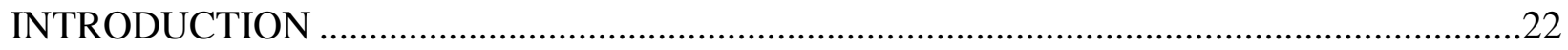

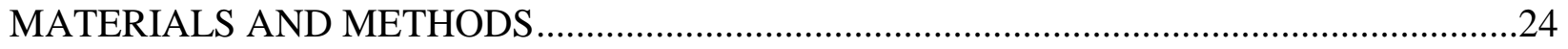

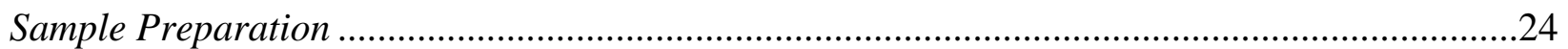

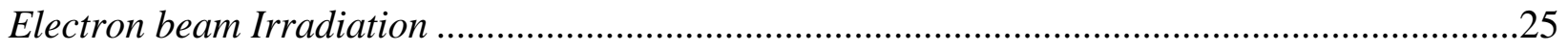

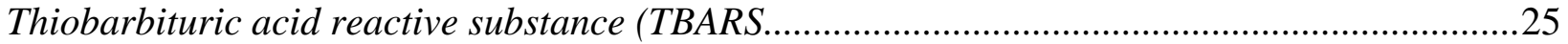

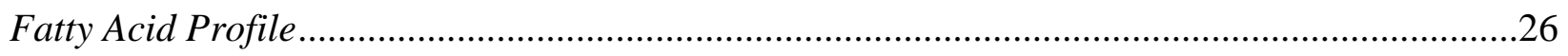

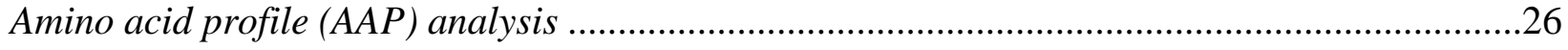

Sodium dodecyl sulfate polyacrylamide gel electrophoresis-SDS-PAGE ...................................27

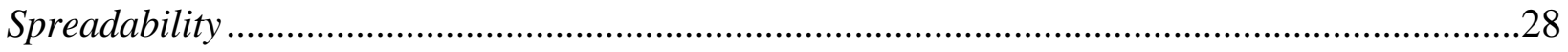

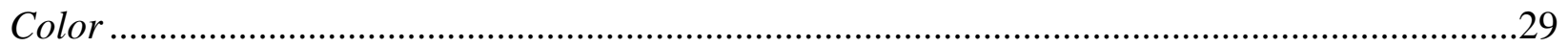

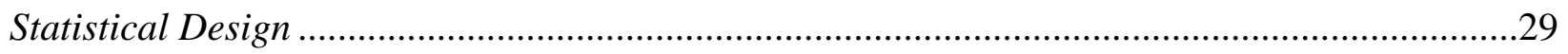

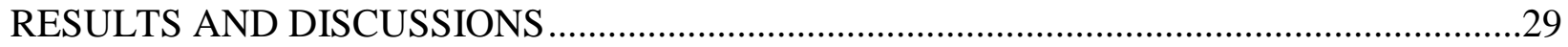

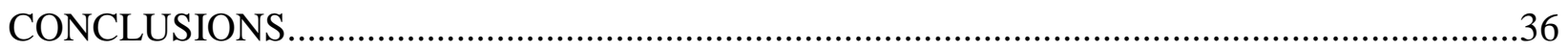

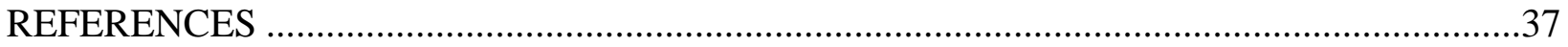




\section{List of Figures}

\section{Chapter 3}

Figure 1. Texture Technologies TA-425 TTC Spreadability Fixture ${ }^{\mathrm{TM}}$

Figure 2. Linear regression of $\mathrm{mg} \mathrm{MDA} / \mathrm{kg}$ sample, expressed as a function of dose

Figure 3. Linear regression of $\mathrm{L}^{*}$-value (lightness), expressed as a function of dose..........

Figure 4. Sodium dodecyl sulfate-polyacrylamide gel electrophoreseis of $45.45 \mu \mathrm{g}$ of peanut butter protein exposed to $0.0,3.1,7.0,27.7 \mathrm{kGy}$ on $15 \%$ Tris- $\mathrm{HCl}$ separating gels 


\section{List of Tables}

\section{Chapter 3}

Table 1. Thiobarbituric acid reactive substances test (TBARS) analyzed by dose and by day. Color absorbance was read at $532 \mathrm{~nm}$ and TBARS values were reported as mg malondialdehyde (MDA) per kg sample

Table 2. Fatty acid analysis of peanut butter treated with different e-beam doses on days-2 and 14 after treatment

Table 3: Amino acid analysis of peanut butter at treated with different e-beam doses

Table 4: Pixel density as \% saturation of protein bands shown by Sodium dodecyl sulfate polyacrylamide gel electrophoresis (SDS-Page). Pixel density was determined by Flurochem ${ }^{\mathrm{TM}}$ 8000 Advanced Fluorescence, Chemiluminescence \& Visible Light Imaging. All treatments were done in triplicate and could not be fit on the same gel therefore Gel 1(Table 4a) compares 0 and 25 kGy while Gel 2 (Table 4b) compares 0, 3, and 7.0 kGy

Table 5a and 5b. Texture analysis of e-beamed peanut butter using a texture analyzer fitted with a cone-shaped probe. Force 1(Table 5a) represents the amount of force exerted as probe penetrates peanut butter. Force 2 (Table 5b) represents the amount of force as probe exits the penetrated peanut butter

Table 6a, 6b, 6c. Color analysis (L*, a*, b*, respectively) of e-beamed peanut butter. .44 


\section{Chapter I}

\section{Introduction}

Salmonella is typically found in animal-based food products; however in the last several years peanut butter and peanut paste have been implicated as the vehicle of transmission in several outbreaks of salmonellosis. The first known outbreak of Salmonella in peanut butter occurred in Australia and led to 15 cases in 1996 (Scheil, 1998). In November 2006, multistate outbreaks of Salmonella Tennessee occurred in various brands of commercial peanut butter manufactured in the same plant, leading to 628 illnesses and 125 hospitalizations but no deaths (CDC, 2007). Peanut paste, a key ingredient in many snack products, was responsible for the 2008 outbreak of Salmonella serotype Typhimurium which resulted in 529 cases including 8 deaths (CDC, 2009). Current industry standard heat treatment methods are not effective at eradicating Salmonella in peanut butter (Shachar and Yaron, 2006); therefore alternative processing methods should be explored.

Electron beam (e-beam) irradiation is a non-thermal food safety and preservation technology that uses ionizing radiation to destroy microorganisms, viruses and insects. Ionizing irradiation has been approved by United States Department of Agriculture (USDA) and Food and Drug Administration (FDA) for the treatment of fish, meat, poultry, fruits, vegetables and spices (FDA, 2009). Hvizdzak and others (2009) demonstrated e-beam radiation to be effective in the inactivation of Salmonella serotypes Tennessee and Typhimurium in peanut butter. Generated by high electrical voltages, electron beams are highly concentrated charged beams of electrons that are characterized by their high efficiency but low penetration depth. One of the major advantages of e-beam irradiation is that it uses electricity, instead of radioactive isotopes which allows it to be turned on and off as needed (Stewart, 2001). 
Ionizing irradiation has been shown to cause flavor, texture, and color changes in some foods. The effects of ionizing irradiation on nut butters have not been published; however there are a number of studies that examine its effect on nuts. Increased lipid oxidation due to irradiation has been observed in hazelnuts (Mexis and Kontominas, 2009), pine nuts (Gölge and Ova, 2008), and almonds (Mexis et al, 2009) which often leads to off-odors and off-flavors in foods. Irradiation is known to degrade proteins by eliciting structural damages to tertiary structures of proteins (Stewart, 2001); however no changes in protein content were seen in almonds (Sánchez-Bel et al, 2006) and cashew nuts (Bhattacharjee et al, 2003). E-beam may cause the breakdown of cellulose leading softening of fruits, vegetables and legumes, as was seen with tropical legumes (Bhat and Sridhar 2008). Color changes as a function of radiation dose were observed in hazelnuts (Mexis and Kontominas, 2009), pine nuts (Gölge and Ova, 2008), almonds (Mexis et al, 2009 and Sánchez-Bel et al, 2006), and cashews (Bhattacharjee et al. 2003). The effect of e-beam radiation on product quality of peanut butter must be determined; therefore the objective of this study was to evaluate the effects of e-beam irradiation on quality parameters of peanut butter over time. 


\section{References}

Bhattacharee P, Singhal RS, Gholap AS, Variyar PS, Bongirwar DR. 2003 Compositional profiles of $\gamma$-irradiated cashew nuts. Food Chemistry 80:159-163

Centers for Disease Control and Prevention. 2007 Multistate outbreak of Salmonella serotype Tennessee infections associated with peanut butter—United States, 2006-2007 MMWR 56:521525

Centers for Disease Control and Prevention. 2009 Multistate outbreak of Salmonella infections associated with peanut butter and peanut butter — containing products—United States, 2008-2009. MMWR 58:1-6

Gölge E, Ova G. 2008 The effects of food irradiation on quality of pine nut kernels. Radiation Physics and Chemistry 77:365-369

Hvizdzak AL, Beamer S, Jaczynski J, Matak KE. Use of electron beam radiation for the reduction of Salmonella enterica Serovars Typhimurium and Tennessee in Peanut Butter. Journal of Food Protection 73 (2):353-357

Mexis SF, Badeka AV, Chouliara E, Riganakos KA, Kontominas MG. 2009 Effect of $\gamma$ irradiation on the physicochemical and sensory properties of raw unpeeled almonds kernels (Prunus dulcis). Innovative Food Science and Emerging Technologies 10: 87-92.

Mexis SF, Kontominas MG. 2009 Effect of $\gamma$-irradiation on the physicochemical and sensory properties of hazelnuts. Radiation Physics and Chemistry 78:407-413

Sánchex-Bel P, Egea I, Romojaro F, Martinez-Madrid C. 2006 Sensorial and chemical quality of electron beam irradiated almonds (Prunus amygdalus). LWT-Food Science and Technology 41: $442-449$

Scheil W, Cameron S, Dalton C, Murray C, Wilson D. 1998. A South Australian Salmonella Mbandaka outbreak investigation using a database to select controls. Austr. N.Z.J. Public Health 22:236-539

Shachar D and Yaron S. 2006. Heat tolerance of Salmonella serovars Agona, Enteritidis, and Typhimumium in peanut butter. Journal of Food Protection 69: 2687-2691

Stewart EM. 2001 Food irradiation Chemistry, Food Irradiation Principles and Applications (pp.37-75) New York, NY: John Wiley \& Sons, Inc.

U.S. Food and Drug Administration. 2009. Food Irradiation Consumer Information. Available at: http://www.fda.gov/Food/FoodIngredientsPackaging/IrradiatedFoodPackaging/ucm135143.htm Accessed 17 May 2010. 
Scheil W, Cameron S, Dalton C, Murray C, Wilson D. 1998. A South Australian Salmonella Mbandaka outbreak investigation using a database to select controls. Austr. N.Z.J. Public Health 22:236-539

Shachar D and Yaron S. 2006. Heat tolerance of Salmonella serovars Agona, Enteritidis, and Typhimumium in peanut butter. Journal of Food Protection 69: 2687-2691

Stewart EM. 2001 Food irradiation Chemistry, Food Irradiation Principles and Applications (pp.37-75) New York, NY: John Wiley \& Sons, Inc.

U.S. Food and Drug Administration. 2009. Food Irradiation Consumer Information. Available at: http://www.fda.gov/Food/FoodIngredientsPackaging/IrradiatedFoodPackaging/ucm135143.htm Accessed 17 May 2010. 


\section{Chapter II}

\section{Review of Literature}

Historically, peanut butter was not considered a high risk food in the spread of Salmonella; however outbreaks of Salmonella in peanut butter and peanut paste products in November 2006 and September 2008 resulted in an estimated 628 and 529 illnesses respectively, including 8 deaths in 2009 (CDC, 2007 and 2009). Peanut butter is currently exposed to thermal heat treatment at a temperature range of $70-75^{\circ} \mathrm{C}$ prior to packaging; however Shachar and Yaron (2006) found that Salmonella is able to survive in peanut butter up to temperatures as high as $90^{\circ} \mathrm{C}$. Increasing the temperature or processing time of thermal pasteurization is likely to induce negative quality effects in peanut butter; therefore alternative processing methods should be explored. Electron beam (e-beam) irradiation is an effective non-thermal processing step for the reduction of Salmonella in peanut butter (Hvizdzak et al. 2009). Before e-beam irradiation can be implemented as a food safety technique for peanut butter, the effect on product quality must be investigated.

\section{Electron Beam Processing:}

Recent outbreaks of food-borne illnesses in ready to eat (RTE) and fresh foods have lead to the need for new methods of food preservation and microbial reduction. Traditional methods of microbial reduction usually depend upon heat treatment that often causes sensory, nutritional, and functional changes that may be detrimental to the quality of fresh and ready to eat foods. Ionizing irradiation is a non-thermal pasteurization method that has been used as an effective method of microbial reduction in some segments of the food industry since 1963 (FDA, 1998). The words "irradiation" and "radiation” are often used interchangeably; however the word 
"irradiation" typically refers to the process of exposing food to ionizing radiation where “radiation” describes a type of energy (Matak and Jaczynski, 2009).

Ionizing radiation uses energy similar to the waves of radio, television, and microwaves; however, the energy produced by ionizing radiation is strong enough to cause ejection of an electron from an atom resulting in the formation of an ion (Matak and Jaczynski, 2009). This causes microbial inhibition by eliciting structural damages (membrane breakdown, DNA conformational changes, protein aggregation etc.) which lead to physiological changes (leakages from membranes, loss of key enzymes, etc.) all of which result in the microorganism's inability to replicate (Manas and Pagan, 2005). Ionizing radiation also induces microbial inhibition indirectly through water radiolysis. In almost all foods water is a significant if not a major component; water also accounts for $50-70 \%$ of a bacterial cell. When water is irradiated, hydroxyl radicals $(\bullet \mathrm{OH})$ are formed which cause further damage to microbial DNA as well as initiates a series of oxidation and reduction reactions in the food itself (Stewart, 2001). Microbial inhibition by ionizing irradiation is a function of dose where "dose" describes the amount of radiation absorbed by the food product; this is generally measured in Grays (G) or kiloGrays (kGy), where 1 Gray= 0.001 kGy= 1 Joule $(\mathrm{J})$ of energy absorbed per kilogram (kg) of irradiated food (Matak and Jaczynski, 2009).

Different forms of ionizing radiation include gamma $(\gamma)$ - ray, electron beam (e-beam) and X-rays, all of which differ in source of energy, efficiency, and penetration. $\gamma$-radiation is produced by radioisotopes (cobalt-60 and cesium-137) and is characterized by its high penetration which allows for its use on foods of greater thickness than e-beam. $\gamma$-irradiation, however, is lengthier process than e-beam which results in great free-radical production due because they are being neutralized at a slower rate; this then causes them to produce greater 
effects on food components. Consumer concerns for safety are also raised in $\gamma$-irradiation due to the use of radioisotopes. E-beam radiation is generated by linear accelerators that produce high voltage electron beams that are accelerated close to the speed of light. E-beam machines are powered by electricity; therefore a major advantage of e-beam is that it can easily be turned on or off like a light bulb and does not require the use of radioactive materials. One of the major disadvantages of e-beam, however, is its low penetration power; therefore its use is only recommended for foods no more than 5-10 centimeters in depth (Stewart, 2001). E-beam can be converted to X-rays by use of a heavy metal target (Stewart, 2001). X-rays have a higher penetration than e-beam; however the efficiency of converting e-beam to X-rays is about $10 \%$. Therefore, the choice between e-beam and X-rays depends on the desired effect: high penetration or high efficiency (Matak and Jaczynski, 2009).

Ionizing radiation is effective at eliminating or reducing bacterial pathogens such as Campylobacter jejuni, Salmonella, Escherichia coli O157:H7, and Listeria monocytogenes (Matak and Jaczynski, 2009). Doses of 10 kGy or less have are effective for pest elimination, inhibition of sprouting, delaying ripening, control of food-born bacterial pathogens, and reduction of spoilage organisms (Matak and Jaczynski, 2009). United States Department of Agriculture (USDA) and the Food and Drug Administration (FDA) have approved the use of irradiation for treatment of fish, meat, poultry, fruits, vegetables and spices (FDA, 2009). However, in some foods, ionizing irradiation has an effect on the macronutrients (lipids, proteins, and carbohydrates) which may result in flavor, color, and texture changes. 


\section{Microbial Inactivation by E-beam}

Hvizdzak and others (2009) demonstrated e-beam to be an effective method for nonthermal inactivation of Salmonella in peanut butter. Samples of commercial brand peanut butter inoculated with approximately 8.0-log CFU/g of Salmonella serotypes Typhimurium and Tennessee were exposed to e-beam irradiation doses ranging from 0-3.1 kGy. Survivors were enumerated on non-selective tryptic soy agar (TSA) and selective xylose-lysine-desoxycholate ager (XLD) media using standard spread-plating method; differences in recovery on TSA and XLD media were then compared to determine if cell injury occurred. E-beam doses of greater than and equal to $0.5 \mathrm{kGy}$ produced significant $(P<0.05)$ reductions in both serotypes Tennessee and Typhimurium on both TSA and XLD. Approximate dose of $3.0 \mathrm{kGy}$ produced a 5.00- and 6.75-log reduction of cells on TSA and XLD, respectively; and a 4.19- and 4.85-log reduction of Salmonella Typhimumium on TSA and XLD, respectively. D-values for Salmonella Tennessee $(0.72 \pm 0.02$ and $0.60 \pm 0.01 \mathrm{kGy}$ on TSA and XLD, respectively) were significantly $(P<0.05)$ lower than that of Salmonella Typhimumium $(0.82 \pm 0.02$ and $0.73 \pm 0.01 \mathrm{kGy}$ on TSA and XDL, respectively) indicating Salmonella Typhimumium to be more resistant to e-beam radiation than Salmonella Typhimumium. D-values for both Salmonella serovars were significantly $(P<0.05)$ greater on TSA. TSA aids the recovery of injured cells; therefore this indicates that e-beam caused cell injury. These results indicate e-beam irradiation is effective at inactivating Salmonella in peanut butter (Hvizdzak et al, 2009).

The effect of e-beam radiation on Salmonella in peanut butter was further investigated to determine recovery rates of serotypes Tennessee and Typhimurium over a 14-day storage period at $22^{\circ} \mathrm{C}$ (Matak et al, 2010). Peanut butter samples, containing 8-log (CFU/g) of either serotype Tennessee or Typhimurium were exposed to e-beam doses ranging from 0-3.1 kGy. Survival 
recovery using standard plating methods on non-selective and selective media was conducted on day 2, 4, 6, 8, and 14. Microbial numbers decreased over time in e-beam treated samples; however significant reductions $(P<0.05)$ were only seen in Salmonella Typhimurium at day 14, indicating that remaining uninjured cells are likely to survive the expected shelf-life of peanut butter. Recovery rates of for both Salmonella Tennessee and Salmonella Typhimurium were significantly higher for nutrient rich TSA media than selective XLD media on day 2; however these differences were not seen in the following days. This indicates that damaged cells were able to repair themselves when promptly exposed to a nutrient-rich environment following ebeam radiation; however they were not able to survive an extended period of time in peanut butter which is a high fat, low water environment (Matak et al, 2010) Even though e-beam irradiation has proven to be beneficial in microbial reduction of Salmonella in peanut butter, the effects of e-beam on the quality of peanut butter have not been determined.

\section{Effect of E-beam on the Quality of Foods}

\section{Lipids}

The effects of radiation on lipids are dependent on parameters such as composition of lipid (saturated or unsaturated), the presence of antioxidants, and aerobic or anaerobic storage conditions (Stewart, 2001). Increased lipid oxidation is a major concern in food irradiation, which leads to off-odors and off-flavors in food. As previously discussed, free-radicals are generated in irradiated food due to water radiolysis and their formation leads to lipid autooxidation (Matak and Jaczynski, 2009). Triglycerides are most prevalent type of lipid; they consist of three fatty acid chains attached to a glycerol backbone. Unsaturated fatty acids are less stable and thus more susceptible to oxidation. Oxidation of unsaturated fatty acids proceeds 
in three stages: initiation, propagation, and termination. Initiation phase occurs when a free radical $(\mathrm{R} \bullet)$ and a hydrogen radical $(\mathrm{H} \bullet)$ are formed. This usually occurs from the methylene group adjacent to the double bond on the fatty acid chain (R), however with ionizing irradiation this reaction is initiated by free radicals formed from water radiolysis. Propagation occurs when a free radical combines with oxygen to form peroxy radicals (ROO•) which removes the hydrogen from the $\mathrm{RH}$ group of other molecules to yield hydroperoxides ( $\mathrm{ROOH}$ and $\mathrm{R} \bullet$ ). The $\mathrm{R}$ - then reacts with the oxygen and thus the cycle repeats until termination (Matak and Jaczynski, 2009). In peanut butter, however, the water activity is very low (aw $=0.51)$ (Hvizdzak and others 2009); therefore irradiation induced lipid oxidation is likely to be lower than in other foods with higher water content.

There are several assays to detect lipid oxidation, some of which include peroxide value (P-value), hexanal content, and thiobarbituric acid reactive substance (TBARS). Peroxides are primary intermediates, while hexanal is a secondary intermediate in lipid-auto oxidation; these are both associated with rancidity caused by oxidation. Thiobarbituric acid reactive substances test measures malondialdehyde (MDA) formation, which is a product of lipid oxidation.

While there are no reported studies that have looked directly at the effects of ionizing irradiation on lipid stability of peanut butter, the effects of irradiation on lipid oxidation in different types of nuts have been reported. Mexis and Kontominas (2009) evaluated the effects of $\gamma$-irradiation on the physicochemical properties in hazelnuts irradiated at doses of 1.0, 1.5, 3.0, 5.0, and 7.0 kGy. Lipid oxidation was dose-dependent, as measured by hydroperoxides, primary oxidation products (peroxide value) and hexanal, a secondary oxidation product. Peroxide values were significantly $(P<0.05)$ increased at all doses above $1 \mathrm{kGy}$ compared to the control. There was also a significant increase in hexanal content at all doses compared to the control. 
Hazelnuts irradiated at $7 \mathrm{kGy}$ produced a 20 -fold and 28-fold increase in peroxide value and hexanal content, respectively. Sensory evaluation by a 51 member untrained panel was done on irradiated hazelnuts, with panelists evaluating color, texture, odor, and taste using a 9-point hedonic scale. Results showed significant dose-dependent $(P<0.05)$ decreases in acceptability based on odor and taste; this is consistent with increase in lipid oxidation and hexanal content which would affect the over-all taste and odor (Mexis and Kontominas, 2009).

Similar results were seen in pine nuts over a 3-month storage period after exposure to $\gamma$ irradiation doses ranging from 0.5 to $5.0 \mathrm{kGy}$ (Gölge and Ova, 2008). Lipid oxidation, as determined by peroxide value, was significantly $(P<0.05)$ increased at doses of 3.0 and $5.0 \mathrm{kGy}$ compared to the control. Peroxide values increased with storage time in all treatments including the control; however significant $(P<0.05)$ increases in peroxide values as a function of storage time were only seen at 3 months for all treatments. Despite increases in lipid oxidation, sensory evaluation done by ranking tests showed no difference in consumer acceptance of flavor, and over-all impression between the control and irradiated pine nuts over a 3-month period; therefore even though lipid oxidation significantly increased with irradiation, changes in flavor and odor were not detected by panelists (Gölge and Ova, 2008).

This is consistent with findings of Mexis and others (2009) who found $\gamma$-irradiation to increase lipid oxidation in almonds as determined by peroxide value and hexanal content. Peroxide values were significantly $(P<0.05)$ increased at doses greater than $0.5 \mathrm{kGy}$ compared to the control and hexanal content was significantly $(P<0.05)$ increased at dose of greater than 1.0 kGy compared to the control. Sensory evaluation on a 9-point hedonic scale was done by a 51 member untrained panel; results showed significant $(P<0.05)$ decreases of scores in taste and 
odor at all doses compared to the control with the least favorable score occurring for taste at doses greater than 3.0 kGy (Mexis et al. 2009).

Al-Bachir (2004) evaluated the effect of $\gamma$-irradiation at doses ranging from 0.5 -2.0 kGy on the chemical and sensory characteristics of walnuts initially after irradiation and after 12 months of storage. There were no significant $(P<0.05)$ changes in lipid oxidation, as determined by peroxide values, immediately after irradiation when compared with the control. After a 12month storage period, peroxide values decreased at doses of $0.5,1.0$, and 1.5 compared to the control; whereas peroxide values increased significantly at a dose of $2.0 \mathrm{kGy}$. Authors gave no plausible explanation for the observed decrease and increase in peroxide values after 12 months storage period. Sensory evaluations conducted on a 5-point scale and completed by an untrained 20-member panel revealed a dose-dependent decrease in flavor and aroma immediately after irradiation and after a 12-month storage period; however these changes were only statistically significant $(P<0.05)$ at a dose of $2.0 \mathrm{kGy}$.

On the contrary, Kashani and Valadon (1984) found only a slight and insignificant $(P>0.05)$ increases in lipid oxidation in pistachio kernels when exposed to $\gamma$-irradiation doses of 5 and 10 kGy compared to the control (Kashani and Valadon, 1984). Byun and others (1995) found similar results in soybean oil extracted from soybeans that were $\gamma$-irradiated at doses up to $10 \mathrm{kGy}$. Result showed no significant $(P>0.05)$ change in peroxide value compared to the control (Byun et al, 1995).

Irradiation-induced lipid oxidation may produce changes in fatty acid composition due to the oxidation of polyunsaturated and monounsaturated fatty acid causing a decrease in unsaturated fatty acids and an increase in saturated fatty acids. Fatty acid analysis of hazelnuts showed irradiation to have a significant $(P>0.05)$ dose-dependent decrease in total 
monounsaturated (MUFA) and total polyunsaturated fatty acid (PUFA) content, while producing a dose-dependent increase in saturated fat content of irradiated hazelnuts (Mexis and Kontominas, 2009). Similarly, a dose-dependent decrease in monounsaturated fatty acids and significant increases in saturated fatty acid were reported by Mexis and others (2009) in almonds exposed to $\gamma$-irradiation at doses ranging from 1.0-7.0 kGy $(P<0.05)$. The increase in saturated fatty acids may be explained by oxidation of MUFAs and PUFA which are more prone to oxidation (Mexis and Kontominas, 2009). However, no statistically significant $(\mathrm{P}<0.05)$ changes were observed in fatty acid analysis of pine nuts (Gölge and Ova, 2008) or in pistachio kernels (Kashani and Valadon, 1984).

\section{Proteins}

Free radicals produced by water radiolysis have the potential to interact with individual amino acids as well as the secondary, tertiary, and quaternary structures of proteins. Radiationinduced reactions in proteins are strongly influenced by their complex structure which includes the folding of peptide chains, disulfide linkages between the chains, hydrogen bonds, hydrophobic bonds, and ionic bonds. Disulfide bonds in the tertiary structure may be cleaved by free radicals action which may cause protein degradation. Radiation usually causes degradation of fibrous proteins to smaller protein fractions, which may involve breakage of $\mathrm{C}-\mathrm{N}$ bonds in the backbone of the peptide chain or splitting of disulfide bonds (Stewart, 2001). Globular proteins usually undergo aggregation because of disturbances of secondary and tertiary structures that expose reactive groups to the action of radiolytic products of water (Urbain, 1986). Radiationinduced protein degradation is determined by a technique called sodium dodecyl sulfate polyacrylamide gel electrophoresis, or SDS-PAGE. This procedure involves the denaturation of 
proteins to their primary structure, and then gel electrophoresis is used to separate and compare the proteins based on molecular size.

Maity and others (2009) evaluated the effects of $\gamma$-irradiation on the composition of edible rice seed protein, amino acids and genomic DNA of grains Oryza sativa L. and Cicer arietinum L. at doses ranging from 0 to $6.0 \mathrm{kGy}$. $\gamma$-irradiation was shown to cause a dosedepended decrease in protein content, as determined by the Lowry method. Results from SDSPAGE also showed a decrease in band intensity at $4 \mathrm{kGy}$ and greater, which is consistent with decrease in protein content. Conversely there was a dose-dependent increase in free amino-acid content, which was likely due to protein degradation (Maity et al, 2009).

Sánchez-Bel and others (2006) reported the effects of e-beam irradiation at doses ranging from 0.0 to $10.0 \mathrm{kGy}$ on the compositional profiles of almonds over a 5-month storage period. Results showed no statistically significant $(P \geq 0.05)$ differences in protein content as a function of e-beam dose or storage time. Bhattacharjee and others (2003) found similar results in the irradiation of cashew nuts at does ranging from $0.0-1.0 \mathrm{kGy}$, with no changes in protein content being observed. These studies however did not report any data on amino acid profiles, nor did they determine if e-beam had any effect on protein aggregation or degradation.

Jaczynski and Park (2004) reported the changes in physicochemical properties of surimi and surimi gels at varying doses of e-beam. Results from SDS-page showed the gradual disappearance of myosin heavy chain (MHC) and a gradual increase of smaller-molecularweight proteins (200-50 kDa) with increases in e-beam dose. These changes are likely due to degradation of MHC into smaller proteins (Jaczynski and Park, 2004).

Huang and others (1997) determined the effect of e-beam irradiation on protein properties of liquid egg yolk during frozen storage. Egg yolks were irradiated at $2.5 \mathrm{kGy}$ and tested at 
intervals during 60 days of frozen storage. Initial reductions in soluble protein were observed in irradiated samples at day 0, however these reductions were not significant $(P>0.05)$. Significant reductions $(P<0.05)$ in soluble protein were seen over time, regardless of treatment. However, even though there was greater initial soluble protein loss in irradiated samples at day 0 ; the rate of soluble protein content loss over time was slower in irradiated samples compared to nonprocessed samples. SDS-PAGE of extracted soluble proteins showed changes in band patterns in both irradiated and non-processed samples as a function of storage time. There were, however, no visible changes in band pattern or intensity between irradiated and non-processed samples (Huang et al, 1997).

No known research has been published on the physiochemical effects of e-beam radiation to the proteins of nut butters; however, Chung and others (2008) exposed natural liquid peanut butter and peanut extract to pulse UV-light (PUV) to determine its effect on allergy-causing peanut proteins. PUV is a high-peak power technology broad spectrum that consists of intense flashes of white light. PUV is used to inactivate microorganisms on the surfaces of fruits and vegetables by causing the formation of pyrimidine dimers which results in DNA damage making microorganisms incapable of replicating (Gomez-Lopez, 2007). Samples were exposed to PUV doses of $1.27 \mathrm{~J} / \mathrm{cm}^{2}$ at $7.6 \mathrm{~cm}$ below the central axis of the UV-lamp for 3 minutes; proteins were identified using SDS-PAGE. Protein bands corresponding to $63 \mathrm{kDa}$ and $50 \mathrm{kDa}$ proteins were hardly seen in the PUV- treated extract and liquid peanut butters compared to the control. There were however no visible changes in any other peanut proteins and pixel densities were not determined. SDS-PAGE indicated the disappearance of these proteins in the PUV-treated samples; this effect was determined to result from the formation of insoluble aggregates or 
participates which were easily seen when the supernatant from PUV-treated samples were allowed to stand at $4^{\circ} \mathrm{C}$ (Chung, 2008).

\section{Texture}

Textural changes in foods due to e-beam radiation vary depending on a foods physiochemical properties. E-beam-induced breaking of disulfide bonds has a firming effect in seafood (Jaczynski and Park, 2004). E-beam is known to break down cellulose which is the form of carbohydrate in the cell wall of fruits, vegetables, and legumes. Loss of firmness, which led to decreased cooking time, was seen in tropical legumes when exposed e-beam radiation at doses greater than $10 \mathrm{kGy}(P<0.05)$ (Bhat and Sridhar 2008). However, sensory evaluations of hazelnuts (Mexis and Kontominas, 2009), pine nuts (Gölge and Ova, 2008), almonds (Mexis et al. 2009), and walnuts (Al-Bachir, 2004) exposed to $\gamma$-irradiation revealed no significant $(P>0.05)$ differences in acceptability based on texture; however these studies did not determine textural changes through instrumental measures.

\section{Color}

Changes in color due to ionizing radiation have been shown in a variety of foods. These changes depend upon the physiochemical composition of the food. Color changes due to irradiation are often determined instrumentally through a colorimeter, which measures color based on lightness ( $\mathrm{L}^{*}$-value), redness ( $\mathrm{a}^{*}$-value), and yellowness ( $\mathrm{b}^{*}$-value). Irradiation of hazelnuts causes a significant decrease in redness $\left(\mathrm{a}^{*}\right)$ and yellowness $\left(\mathrm{b}^{*}\right)$ (Mexis and Kontominas, 2009). The same is true for pine nuts, with irradiation causing a decrease in yellowness and redness (Gölge and Ova, 2008). No significant changes in $\mathrm{a}^{*}$ or $\mathrm{b}^{*}$ values were 
seen with the irradiation of almonds; however radiation exposure was responsible for a significant $(P<0.05)$ decreases in lightness ( $L^{*}$-value) (Mexis et al. 2009). Cashew nuts irradiated at varying doses ranging from 0.25 to $1.00 \mathrm{kGy}$ had increased yellowness as a function of dose and storage time (Bhattacharjee et al. 2003). Sánchez-Bel and others (2006) observed slight darkening of almonds as a function of dose and storage time; however these changes were not significant $(P \geq 0.05)$. The increase in darkness may have been due to breakdown of protein and carbohydrates leading to the production of carbonyl and amino compounds, which could react in a Maillard reaction to produce color compounds (Mexis et al. 2009). Maillard reactions typically require a heat source in order for carbonyls and amino acids to react; however Oh and others

(2005) reported the browning of sugar amino-acid solutions when exposed to $\gamma$-radiation at doses up to $30 \mathrm{kGy}$.

Despite the color changes detected instrumentally, sensory evaluation of hazelnuts (Mexis and Kontominas, 2009), pine nuts (Golge and Gulden, 2008), and almonds (Mexis et al. 2009), showed no significant $(P>0.05)$ differences in acceptance based on color. On the contrary Sánchez-Bel and others (2006) reported significant $(P \leq 0.05)$ decrease in sensory evaluation color scores on a 5-point scale for almonds irradiated at $10 \mathrm{kGy}$. However this sensory evaluation was done by a trained 7-member panel compared to the other studies that used larger groups of untrained panelists.

\section{Summary}

Electron beam (e-beam) irradiation is an effective non-thermal processing step for the reduction of Salmonella in peanut butter. Ionizing radiation is known to produce changes in quality parameters of nuts, which may affect consumer acceptance. Therefore, the quality effects 
of e-beam radiation on peanut butter must be determined prior to its implementation as a food safety technique. The objective of this study was to evaluate the effects of e-beam irradiation on certain quality parameters of peanut butter. 


\section{References}

Al-Bachir M. 2004 Effect of gamma irradiation on fungal load, chemical and sensory characteristics of walnuts (Juglans regia L.) Journal of Stored Products Research 40: 355-362

Bhat R, Sridhar KR. 2008 Effect of electron beam irradiation on the quality characteristics of an economically valued tropical legume Mucuna Prurines. Electronic Journal of Environmental, Agricultural and Food Chemistry 7 (12): 2578-2581

Bhattacharee P, Singhal RS, Gholap AS, Variyar PS, Bongirwar DR. 2003 Compositional profiles of $\gamma$-irradiated cashew nuts. Food Chemistry 80:159-163

Byun MW. 1995 Physicochemical properties of soybean oil extracted from $\gamma$-irradiated soybeans. Radiation Physics and Chemistry 46 (4-6): 659-662.

Centers for Disease Control and Prevention. 2007 Multistate outbreak of Salmonella serotype Tennessee infections associated with peanut butter—United States, 2006-2007 MMWR 56:521525

Centers for Disease Control and Prevention. 2009 Multistate outbreak of Salmonella infections associated with peanut butter and peanut butter—containing products—United States, 2008-2009

Chung S, Yang W, Krishnamurthy K. 2008 Effects of Pulsed UV-light on Peanut Allergies in Extracts and Liquid Peanut Butters. Food Chemistry 73 (5): C400-C404

Gomez-Lopez V, Ragaert P, Debevere J, Devlieghere F. 2007 Pulsed light for food decontamination: a review. Trends in Food Science \& Technology 18:464-473

Gölge E, Ova G. 2008 The effects of food irradiation on quality of pine nut kernels. Radiation Physics and Chemistry 77:365-369

Huang S, Herald TJ, Mueller DD.1997 Effect of electron beam irradiation on physical, physicochemical, and functional properties of liquid egg yolk during frozen storage. Poultry Science 76:1607-1615

Hvizdzak AL, Beamer S, Jaczynski J, Matak KE. 2010 Use of electron beam radiation for the reduction of Salmonella enterica Serovars Typhimurium and Tennessee in Peanut Butter. Journal of Food Protection 73 (2):353-357

Jaczynski J, Park JW. 2004 Physicochemical changes in Alaska Pollock Surimi and Surimi Gel as affected by Electron Beam. Journal of Food Science 69 (1):FCT53-FCT57

Kashani GG, Valadon RG. 1984 Effects of gamma irradiation on the lipids, carbohydrates, and proteins of Iranian pistachio kernels. Journal of Food Technology 19:631-638 
Maity JP. 2009 Effects of gamma irradiation on edible seed protein, amino acids and genomic DNA during sterilization. Food Chemistry 114:1237-1244

Matak KE, Hvizdzak AL, Beamer S, Jaczynski J. 2010. Recovery of Salmonella enterica Serovars Typhimuium and Tennessee in Peanut Butter after Electron Beam Exposure. Journal of Food Science. Accepted for Publication.

Matak KE and Jaczynski J.2009. Food Preservation with Electron Beam. Food Science Research and Technology. (pp. 229-245) New York, NY: Nova Science Publishers Inc.

Mexis SF, Badeka AV, Chouliara E, Riganakos KA, Kontominas MG. 2009 Effect of $\gamma$ irradiation on the physicochemical and sensory properties of raw unpeeled almonds kernels (Prunus dulcis). Innovative Food Science and Emerging Technologies 10: 87-92.

Mexis SF, Kontominas MG. 2009 Effect of $\gamma$-irradiation on the physicochemical and sensory properties of hazelnuts. Radiation Physics and Chemistry 78:407-413

Oh S-H, Lee Y-S, Lee J-W, Kim MR, Yook H-S, Byun M-W 2005 The effect of $\gamma$-irradiation on non-enzymatic browning reaction in the aqueous model solution. Food Chemistry 92 (2): 357363

Sánchex-Bel P, Egea I, Romojaro F, Martinez-Madrid C. 2006 Sensorial and chemical quality of electron beam irradiated almonds (Prunus amygdalus). LWT-Food Science and Technology 41: 442-449

Scheil W, Cameron S, Dalton C, Murray C, Wilson D. 1998. A South Australian Salmonella Mbandaka outbreak investigation using a database to select controls. Austr. N.Z.J. Public Health 22:236-539

Shachar D and Yaron S. 2006. Heat tolerance of Salmonella serovars Agona, Enteritidis, and Typhimumium in peanut butter. Journal of Food Protection 69: 2687-2691

Stewart EM. 2001 Food irradiation Chemistry, Food Irradiation Principles and Applications (pp.37-75) New York, NY: John Wiley \& Sons, Inc.

U.S. Food and Drug Administration. 2009. Food Irradiation Consumer Information. Available at: http://www.fda.gov/Food/FoodIngredientsPackaging/IrradiatedFoodPackaging/ucm135143.htm Accessed 17 May 2010. 


\section{Chapter III}

The Effects of Non-thermal Electron Beam Irradiation on Quality Indicators of Peanut

Butter.

A. El-Rawas, A. Hvizdzak, M. Davenport, S. Beamer, J. Jaczynski, K.E. Matak

Affiliation:

Division of Animal and Nutritional Sciences, West Virginia University, P.O. Box 6108,

Morgantown, WV 26508

Key Words: peanut butter, electron beam irradiation, quality effects 


\section{Introduction}

Outbreaks of Salmonella in peanut butter and peanut paste products led to an estimated 628 reported cases in 2007 and 529 cases, including 8 deaths in 2009 (Center for Disease Control and Prevention, 2007 and 2009). The current industry standard thermal pasteurization method is not effective at eradicating Salmonella in peanut butter (Shachar and Yaron, 2006); therefore alternative processing methods should be explored. Electron beam (e-beam) irradiation is a nonthermal technology that exposes food products to ionizing radiation to destroy microorganisms, viruses, or insects. Ionizing radiation uses energy similar to the waves of radio, television, and microwaves; however, the energy produced by ionizing radiation is strong enough to cause ejection of an electron from an atom resulting in the formation of an ion (Matak and Jaczynski, 2009). This causes microbial inhibition by eliciting structural damages (membrane breakdown, DNA conformational changes, protein aggregation etc.) which lead to physiological changes (leakages from membranes, loss of key enzymes, etc.) all of which result in the microorganism’s inability to replicate (Manas and Pagan, 2005). Ionizing irradiation has been used in the food industry since 1963 (FDA, 1998) and is approved by the United States Department of Agriculture (USDA) and Food and Drug Administration (FDA) for the treatment of fish, meat, poultry, fruits, vegetables and spices (FDA, 2009). Hvizdzak and others (2009) demonstrated ebeam to be an effective method for non-thermal inactivation of Salmonella in peanut butter. Electron beams are highly concentrated charged beams of electrons that are generated by electrical voltages. E-beam irradiation is characterized by its low penetration and high efficiency. One major advantage of e-beam irradiation is that it uses electricity, instead of radioactive isotopes allowing it to be turned on and off as needed (Stewart, 2001). 
Ionizing irradiation is known to illicit flavor, texture and color changes in some foods. No known studies have been published that examine the effect of ionizing irradiation on nutbutters; however there are a number of studies that examine its effect on nuts. The effects of radiation on lipids are dependent on parameters such as composition of lipid (saturated or unsaturated), the presence of antioxidants, and aerobic or anaerobic storage conditions (Stewart, 2001). Increased lipid oxidation due to ionizing irradiation leads to off-odors and off-flavors in foods; $\gamma$-irradiation has significantly increased lipid oxidation and decrease acceptability based on odor and taste in hazelnuts (Mexis and Kontominas, 2009), pine nuts (Gölge and Ova, 2008), and almonds (Mexis et al, 2009).

A major effect of e-beam irradiation is the production of free radicals, which are produced by the splitting of water molecules (water radiolysis) (Matak and Jaczynski, 2009). Free-radicals then have the potential to interact with individual amino acids as well as the secondary, tertiary, and quaternary structures of proteins. Radiation-induced reactions in proteins are strongly influenced by their complex structure which includes the folding of peptide chains, disulfide linkages between the chains, hydrogen bonds, hydrophobic bonds, and ionic bonds. Disulfide bonds in the tertiary structure may be cleaved by free radicals action which may cause protein degradation (Stewart, 2001). Radiation usually causes degradation of fibrous proteins to smaller protein fractions, which may involve breakage of C-N bonds in the backbone of the peptide chain or splitting of disulfide bonds (Stewart, 2001). Globular proteins usually undergo aggregation because of disturbances of secondary and tertiary structures that expose reactive groups to the action of radiolytic products of water (Urbain, 1986). Radiation-induced protein aggregation and degradation is determined by a technique called sodium dodecyl sulfate polyacrylamide gel electrophoresis, or SDS-PAGE. This procedure involves the denaturation of 
proteins to their primary structure, and then gel electrophoresis is used to separate and compare the proteins based on molecular size.

E-beam has the potential to cause textural softening of fruits, vegetables and legumes through the break down of cellulose, as was seen with tropical legumes (Bhat and Sridhar 2008). Change in color as a function of radiation dose were observed in hazelnuts (Mexis and Kontominas, 2009), pine nuts (Gölge and Ova, 2008), almonds (Mexis and others, 2009 and Sánchez-Bel and others, 2006), and cashews (Bhattacharjee et al. 2003). The effect of e-beam radiation on product quality of peanut butter should be determined; therefore the objective of this study was to evaluate the effects of e-beam irradiation on quality parameters of peanut butter over time.

\section{Materials and Methods}

\section{Sample Preparation:}

A commercial brand of creamy peanut butter was purchased at a local grocery store (Morgantown, WV, USA). The composition of the peanut butter (in order listed on product label) was roasted peanuts, sugar, hydrogenated vegetable oils, salt, partially hydrogenated cottonseed oil. Both 16 oz (17” x 20”) and 4oz (4”x 6”) Ampac flexible heat-sealable multipurpose pouches (Ampac Corp. Cincinnati, OH, U.S.A) were filled with 25 and 10 grams of peanut butter respectively, and sealed. Peanut butter was evenly distributed throughout the bag to promote even absorption of the e-beam. The 25 gram bags were used to measure color, texture, lipid oxidation, and protein structure. The 10 gram samples were used for fatty acid and amino acid analysis. All pouches were labeled with the target dose of e-beam irradiation and the day in which the sample would be evaluated. Bags were separated by target dose, placed in plastic 
containers (Ziplock 91⁄2 cup containers, SC Johnson Products Racine, WI, USA.) and stored at controlled temperature of $22^{\circ} \mathrm{C}$ (Classic C24, New Brunswick Scientific Co., Inc., Edison, NJ USA) until shipping to the irradiation facility.

\section{Electron beam Irradiation}

Samples were packed in a Styrofoam cooler box and shipped overnight to e-beam processing facility (Sterigenics Intl., San Diego, CA, USA). The target doses of irradiation were: 0, 3.0, 7.0, and $25 \mathrm{kGy}$. Doses were confirmed to be 0.0, 3.2, 7.0, and $27.7 \mathrm{kGy}$ using film dosimeters (FWT-60 series radiochromatic dosimeters, Far West Technology, Inc., Goleta, CA). After treatment, samples were shipped overnight back to West Virginia University. Upon arrival samples were stored at room temperature $22^{\circ} \mathrm{C}$ (classic, New Brunswick Scientific Co., Inc., Edison, NJ USA). The total time between irradiation and arrival at West Virginia University was 2 days (48 hours). Commencement of analyses began 3 days after treatment (day 3).

\section{Thiobarbituric acid reactive substance (TBARS)}

Indicators of lipid oxidation were measured by a TBARS assay of malondialdehyde (MDA) according to a modified Yu and Sinnhuber (1957) for days 3, 5, 7, 9, and 15. Color absorbance was read at $532 \mathrm{~nm}$ using a spectrophotometer (Life Science UV/vis spectrophotometer Model DU 530, Beckman Coulter, Fullerton, CA, USA). Results were

reported as mg of malondialdehyde/kg of sample and were calculated using the following equation: Sample TBARS $=$ Ks x A x 5/ Wt (A=absorbance of sample, Wt= exact sample weight, Ks= constant obtained from slop of the standard curve.) 
Fatty Acid Profile Analysis

Fatty acid profiles were done on samples on day-3 and day-15. Samples were stored at a temperature of $-80^{\circ} \mathrm{C}$ to limit fatty acid degradation, until the time of shipping. Samples were packed in dry ice and shipped to the University of Missouri, Experiment Station Chemical Laboratories where fatty acid profile was performed in triplicate according to the Association of Official Analytical Chemists methods (1995). The acidic hydrolysis method (AOAC 996.06) was used to extract fat and fatty acids from biomass. To minimize oxidative degradation of fatty acids during analysis, pyrogollic acid was added. Triglyceride, triundecanoin (C11:0), was used as internal standard. Using boron trifluoride (BF3) in methanol, fat was extracted into ether, and then methylated into fatty acid methyl esters (FAMEs). Against the C11:0 internal standard, FAMEs were quantitatively measured by capillary gas chromatography. Gas-liquid chromatography (Agilent Technologies, Model 7890A) equipped with a 7683 B series Injector were used to analyze all the samples. Helium was used as the carrier gas with a $0.75 \mathrm{~mL} / \mathrm{min}$ flow rate. The temperature program for separations began at $100^{\circ} \mathrm{C}$, held for $4 \mathrm{~min}$, increased to $240^{\circ} \mathrm{C}$ at $3^{\circ} \mathrm{C} / \mathrm{min}$ and held at $15^{\circ} \mathrm{C}$ for 15 minutes. Injector and detector temperatures were 225 and $285^{\circ} \mathrm{C}$. Peaks were identified by comparing their retention times with references. Total fat was calculated as sum of individual fatty acids expressed as triglyceride equivalents.

\section{Amino acid profile (AAP) analysis}

The control and all the treatments from day-15 were analyzed for a full AAP according to the AOAC method 982.30 E (1995). The samples were freeze-dried and subjected to the following three types of hydrolysis: acid hydrolysis with $6 \mathrm{~N} \mathrm{HCl}$ at $110^{\circ} \mathrm{C}$ for $24 \mathrm{~h}$, performic 
acid oxidation at $0-5^{\circ} \mathrm{C}$ overnight followed by acid hydrolysis ( $6 \mathrm{~N} \mathrm{HCl}$ at $110^{\circ} \mathrm{C}$ for $24 \mathrm{~h}$ ), and alkaline hydrolysis with fresh $4.2 \mathrm{~N} \mathrm{NaOH}$ at $110^{\circ} \mathrm{C}$ for $22 \mathrm{~h}$. Following the hydrolysis, amino acids were quantified using the Beckman Amino Acid Analyzer (model 6300, Beckman Coulter, Inc., Fullerton, CA) employing sodium citrate buffers as step gradients with the cation exchange post-column ninhydrin derivatization method. The data are reported as mean values of at least three replicates and the mean values expressed as grams per 100 grams sample (dry weight basis).

Sodium dodecyl sulfate polyacrylamide gel electrophoresis-SDS-PAGE

SDS-PAGE is a technique used to separate proteins according to their electrophoretic mobility, which is a function of polypeptide length and molecular weights.. By separating the proteins, the pixel density of each protein can be compared between the treatments and controls. Therefore protein degradation due to irradiation can be assessed.

SDS-PAGE was conducted on the control (untreated peanut butter) and each e-beam dose at day-15. Protein concentration of peanut butter was estimated to be $250 \mathrm{mg} / \mathrm{mL}$ based on the nutrient facts label. The samples were diluted to $\sim 6 \mathrm{mg} / \mathrm{mL}$, then vortexed until homogenous. After achieving homogeneity, $500 \mu \mathrm{l}$ of sample was added to $950 \mu \mathrm{l}$ of laemmli sample buffer (Bio-Rad Laboratories, Hercules, CA)+ $50 \mu \mathrm{l}$ of 2-mercaptoethanol (Bio-Rad Laboratories, Hercules, CA). Samples were vortexed and heated in $37.7^{\circ} \mathrm{C}$ water bath for $10 \mathrm{~min}$. Samples were cooled and stored at $-80^{\circ} \mathrm{C}$ until gel electrophoresis could be conducted.

The protein concentration of each diluted sample used was determined using the Biuret procedure (Gornall et al. 1949). Due to the collection of peanut sediment, the samples were filtered using filter paper (Whatman 40 ashless circles, Whatman International Ltd Maidstone England) prior to reading the absorbance. From the protein concentration of each sample, the 
amount of each sample to load in gel wells was calculated to assure that the same amount of protein from each sample was being run through electrophoresis.

Two 15\% Tris-HCl separating gels (Ready Gels for electrophoresis, Bio-Rad Laboratories, Hercules, CA) were loaded with $45.45 \mu \mathrm{g}$ of protein from each sample. Gels were run in a Mini-Protein 3 Cell (Bio-Rad, Laboratories, Hercules CA) at a constant $200 \mathrm{~V}$ and a 15 to $20 \mathrm{~mA}$ current using a PowerPac Basic power supply (Bio-Rad Laboratories, Hercules CA) for 25 minutes. Gels were then placed in staining solution (Bio-Safe Coomassie, G-250 stain, Bio-Rad Laboratories, Hercules CA) and were placed in shaker (C24 Incubator Shaker, New Brunswick Scientific, Edison NJ, USA) running at 50 rpm for 3 hours. Gels were then rinsed and placed in distilled water until the pixel density could be read.

Gels were scanned and the pixel density of visible proteins bands were determined using the Flurochem ${ }^{\mathrm{TM}} 8000$ Advanced Fluorescence, Chemiluminescence \& Visible Light Imaging (Alpha Innotech Corporation, San Leanodro, CA).

\section{Spreadability}

Changes in spreadability by e-beam dose and storage time was measured over a 15-day period using a cone-shaped probe, (TA-425 TTC Spreadability Fixture ${ }^{\mathrm{TM}}$, Texture Technologies Corp. Scarsdale, NY USA) in conjunction with TA-HDi analyzer (Texture Technologies Corp. Scarsdale, NY USA). The probe is a matched set of male and female acrylic $90^{\circ}$ cones (Figure 1). Approximately eight grams of peanut butter was used for each test. The test involved the male cone traveling $49.0 \mathrm{~mm}$ from a fixed position of $50.0 \mathrm{~mm}$ at a speed of $3.0 \mathrm{~mm} / \mathrm{sec}$ until male and female cones were separated by $1 \mathrm{~mm}$ causing the peanut butter to ooze out the side. The positive value describes the force in grams as the probe inserted the peanut butter and the 
negative value describes the force in grams of the probe returning to its original position.

Additional settings were based on instructions of the manufacturer.

\section{Color}

Color changes as a result of e-beam irradiation were monitored over a 14-day period. Color assessments were conducted using a chromameter (Model CR-300; Minolta Camera Co. Ltd., Osaka Japan) calibrated with a standard white plate No.21333180 (CIE L* 93.1; a* 0.3135; b* 0.3198). Color was measured directly through the unopened bags of untreated peanut butter on days 3, 5, 7, 9, and 15. Values for L* (lightness; scale 0-100), a* (intensity of redness; scale: $-60-+60$ ), and b* (intensity of yellow color; scale: $-60-+60$ ) were measured in triplicate for each treatment and day.

\section{Statistical Design}

All assays were performed in triplicate. Data was analyzed as a function of storage time and dose. One-way analysis of variance and linear regression was performed. Tukey’s honestly significant difference test was used to determine differences $(P<0.05)$ (JMP 8, SAS Institute, Cary NC USA).

\section{Results and Discussion}

\section{Effect on Lipids}

Thiobarbituric acid reactive substance (TBARS) and Fatty Acid Profile

Results from TBARS on day-3 showed a dose-dependent increase in the formation of malondialdehyde (MDA) at all doses compared to the control (Table 1 and Figure 2); however, 
by the end of the two week storage periods, there were no significant differences $(\mathrm{P}>0.05)$ in MDA content at doses $\leq 7.0 \mathrm{kGy}$, compared to the control. MDA formation was highest at an extreme dose of $27.7 \mathrm{kGy}$, where MDA formation was more than twice that of the control at all days tested. Despite measured increases in MDA as a function of e-beam dose which indicates lipid oxidation; results from fatty acid analysis showed no significant $(P>0.05)$ differences in major fatty acids, total saturated fatty acid content, total unsaturated fatty acid content, total monounsaturated fatty acid content, or total polyunsaturated fatty acid content as a function of dose or storage time (Table 2); these results are inconsistent with results from TBARS which indicate lipid oxidation. If lipid oxidation had occurred, monounsaturated and polyunsaturated, fatty acids, which are high in peanut butter, would be expected to undergo oxidation first; therefore a decrease in unsaturated fatty acid content with increase in saturated fatty acid content would be expected. This was the case in $\gamma$-irradiated hazelnuts (Mexis and Kontominas, 2009) and almonds (Mexis and others, 2009) where lipid oxidation, as measured by peroxide values $(P<0.05)$, was observed in conjunction with significant reductions in unsaturated fatty acid content followed by increases saturated fatty acid content. However lipid oxidation does not always cause significant changes in lipid composition, as was observed in $\gamma$-irradiated pine nuts (Gölge and Ova, 2008) where significant $(P<0.05)$ increases in peroxide values, indicating lipid oxidation led to no significant $(P>0.05)$ changes of fatty acid composition. In this case, $\gamma$ irradiation may have cause significant increase in lipid oxidation products without causing significant change in lipid composition.

TBARS is an assay of MDA, which is measured through color absorbance using a spectrophotometer; therefore the measured increase in MDA may be influenced by the independent e-beam induced color changes which were observed (Table 6). Lipid oxidation 
may be further confirmed by the measurement of peroxide value; however, results from lipid profile confirm that e-beam had limited effect on lipid oxidation in peanut butter. This contradicts studies that show $\gamma$-irradiation to produce significant alterations in fatty acid composition of hazelnuts (Mexis and Kontominas, 2009) and almonds (Mexis and others, 2009); these variations may be explained by the differences in processing of $\gamma$-irradiation compared to e-beam. In e-beam the production of free-radicals occurs rapidly with a short time frame; therefore free-radicals are neutralized more rapidly and their potential to interact with food components is minimized. $\gamma$-irradiation is a more lengthy process where free-radicals are produced at a slower rate and are neutralized more slowly; therefore, they have more potential to interact with food components.

\section{Effect on Protein}

\section{Amino Acid Profile}

The amino acid profile showed no significant $(P>0.05)$ differences in crude protein or total protein as a function of e-beam dose (Table 3). Similar results were reported by SánchezBel and others (2006) who reported e-beam irradiation at doses up to $10 \mathrm{kGy}$ had no effect on total protein content in almonds $(P>0.05)$. Irradiation at doses up to $1.0 \mathrm{kGy}$ was reported to produce no changes $(P>0.05)$ in total protein content of cashew nuts (Bhattacharee et al, 2003). This is likely due to the low moisture content of peanut butter and other nuts, which minimizes the production of free radicals therefore minimizing the effect of radiation on protein degradation. Significant reductions in serine $(P<0.05)$ were observed at all doses compared to the control

(Table 3); Tyrosine decreased significantly $(P<0.05)$ at e-beam doses of 7.0 and $27.7 \mathrm{kGy}$. Histidine and arginine concentrations were significantly reduced at 3.2 kGy e-beam dose; 
however no significant differences were seen at other doses. Histidine is known to be more radio-sensitive than other amino acids and is likely to undergo deamination (Stewart, 2001). No changes, however, were observed in sulfur-containing amino acids (methionine and cysteine) ( $P>0.05$ ), which are known to be radiation-sensitive (Stewart, 2001). Other changes in amino acid may be due to the e-beam-induced free-radical formation, which may have resulted in deamination of certain amino acids. Although changes in some amino acids were shown to be significantly different than the control, the overall differences amounted to less than $5 \%$ or a few hundredths of a gram.

Sodium dodecyl sulfate polyacrylamide gel electrophoresis-SDS-PAGE

SDS-PAGE in 15\% polyacrylamide gel (Figure 4) showed no differences in band patterns between treatments. Significant $(P<0.05)$ reductions in band pixel densities (amount of protein) of higher molecular weight proteins, band A, B, and C, were seen at a dose of $27.7 \mathrm{kGy}$ compared to the control and other treatments (Table 4), suggesting protein degradation of peanut protein at e-beam dose of $27.7 \mathrm{kGy}$; increases in band pixel densities of lower molecular weight bands were not seen, suggesting that protein degradation products may have been so small that they were ran off the gel. Disulfide bonds in the tertiary structure may be cleaved by free radicals action which may cause protein degradation (Stewart, 2001); however the use of SDS and 2-mercaptoethanol denature proteins into their primary structure by breaking hydrophobic interactions and disulfide bond; therefore these bonds cannot be determined through SDS-PAGE. Thus, e-beam induced protein degradation occurred due to the breakage of C-N bonds in the backbone of the peptide chain (Stewart, 2001). Protein degradation was only observed at a high dose of $27.7 \mathrm{kGy}$; this is likely due to the low water activity of peanut butter, which minimized 
the production of free-radicals thus limiting protein degradation. Despite significant changes in pixel density at e-beam dose of $27.7 \mathrm{kGy}$; all protein bands are visible on SDS-PAGE. In addition, the amino acid profile showed no significant decreases in crude protein or total protein content; therefore total protein degradation is likely to be small.

Similar results were reported by Huang and others (1997) who observed no visible changes in band pattern or intensity as in irradiated samples verses the control in SDS-PAGE of liquid egg yolk exposed to 2.5 kGy of e-beam radiation. On the contrary, Maity and others (2009) observed reductions in band intensity on edible rice seed irradiated at doses of $4 \mathrm{kGy}$, which corresponded to a significant reduction in protein content. Likewise in surimi and surimi gels ebeam irradiated at doses of 1.0- 25.0 kGy, Jaczynski and Park (2004) reported a gradual disappearance of myosin heavy chain corresponding to a gradual increase of smaller molecular weight proteins, indicating degradation of larger proteins into smaller ones. Chung and others (2008) determined protein degradation through SDS-PAGE of liquid peanut butter exposed to $1.27 \mathrm{~J} / \mathrm{cm}^{2}$ of pulse UV-light (PUV) for 3 minutes; SDS-PAGE showed disappearance of protein bands corresponding to $63 \mathrm{kD}$ in PUV- treated samples, indicating protein degradation.

\section{Spreadablilty/Texture}

Spreadability of peanut butter was measured by the amount of force (g) required to penetrate peanut butter (force 1) and amount of force exerted when exiting (force 2) peanut butter (Table $\mathbf{5 a}$ and $\mathbf{5 b}$ ). Decreases in force 1 , indicating softening of peanut butter, were observed at doses of 7 and $27.7 \mathrm{kGy}$ on days 8 and 14(P<0.05), with no other changes being observed as a function of dose on all other days $(P>0.05)$. Decreases in force $2(P<0.05)$ were observed day 8 (Table 5b), with no other changes being observed as a function of dose on all 
other days. Significant $(P<0.05)$ decreases in force 1 and force 2 were observed as a function of storage time at all doses including the control (Table 5a and 5b). These results indicate that in the storage period had a greater effect on softening of peanut butter than that of e-beam dose; this may have been due to separation of lipid emulsion over time. Similarly, sensory evaluation $\gamma$ irradiation of hazelnuts (Mexis and Kontominas, 2009), pine nuts (Gölge and Ova, 2008), almonds (Mexis et al. 2009), and walnuts (Al-Bachir, 2004) revealed irradiation to have little effect on texture, with no significant $(P<0.05)$ differences being observed in acceptability based on texture. Bhat and Sridhar (2008), however, reported loss of firmness in tropical legumes when exposed to e-beam radiation at doses greater than $10 \mathrm{kGy}$; this was likely due to breakdown of cellulose.

Color

Color values for irradiated and non-irradiated peanut butter are shown in Table 6. Darkening of peanut butter was observed as e-beam dose increased with significant $(P<0.05)$ decreases in L-values (lightness) being observed at doses greater than and equal to $3.2 \mathrm{kGy}$ on day 8 and at doses greater than and equal to $7.0 \mathrm{kGy}$ at days 4, 6, and 14; however significant decreases in L-values were only observed at a dose of $27.7 \mathrm{kGy}$ for day 2 (Table 6a). Linear regression showed darkening of peanut butter as a function of dose (Figure 3); however these changes were maintained and did not worsen over time. Mexis and others (2009) reported significant $(P<0.05)$ reductions in $L$-values of almonds at irradiation doses of 5 and $7 \mathrm{kGy}$; likewise, Sanchez-Bel and others (2006) reported insignificant $(P>0.05)$ darkening of almonds as a function of irradiation at doses up to $10 \mathrm{kGy}$. Darkening is likely due to the breakdown of protein and carbohydrates into carbonyl and amino acids which then react in a Maillard reaction, 
or non-enzymatic browning (Mexis and others, 2009). Maillard reactions typically require a heat source in order for carbonyls and amino acids to react; however Oh and others (2005) reported the browning of sugar amino-acid solutions when exposed to $\gamma$-radiation at doses up to $30 \mathrm{kGy}$.

Reductions in a*-values (redness) were observed at all doses on days 2, 6, 8, $14(P<0.05)$; however on day-4 significant $(P<0.05)$ reductions in a*-values (redness) were only observed at 27.7 kGy (Table 6b). Lower b*-values (yellowness) (Table 6c) were observed as a dose increased; however significance was only observed on day 2, 6, 8, and 14. In hazelnuts, Mexis and Kontominas (2009) also reported decreases in redness and yellowness as a function of irradiation dose; however these changes were only significant at $7 \mathrm{kGy}$ for yellowness. Likewise, Gölge and Ova (2008) reported significant $(P<0.05)$ changes in L-value and b*-value as a function of dose.

Spectrophotometric measurements indicated color changes in irradiated peanut butter over time; however, these changes were not consistent and not always significant. Casual observations by experimental team were not able to detect changes in color. Furthermore, color commonly varies among peanut butter brands and types; therefore these color changes may not affect consumer preferences. As was the case in irradiated hazelnuts (Mexis and Kontominas, 2009), pine nuts (Gölge and Ova, 2008), and almonds (Mexis, et al. 2009), where sensory evaluations from these studies reported no significant $(P>0.05)$ differences in acceptance based on color despite significant $(P<0.05)$ color changes which were detected instrumentally as a function dose. 


\section{Conclusions}

The results from this study demonstrate e-beam irradiation to produce significant dosedependent changes in color, amino acid profile, and protein degradation when applied to peanut butter. No changes were observed in total protein content, or total saturated and unsaturated fatty acid content. Changes in parameters tested were shown over storage period of 14 days; however trends as a function of storage time were inconsistent. Therefore, it is unclear whether the effects initiated in peanut butter by e-beam exposure would worsen over the duration of the products shelf-life. E-beam irradiation is a promising food safety technique in the pasteurization of peanut butter, however further exploration into its effects as well as sensory evaluations are recommended. 


\section{References}

Al-Bachir M. 2004 Effect of gamma irradiation on fungal load, chemical and sensory characteristics of walnuts (Juglans regia L.) Journal of Stored Products Research 40: 355-362

Association of Official Analytical Chemists. Official Methods of Analysis. 16th ed. Association of Official Analytical Chemists, Washington, D.C., 1995.

Bhat R, Sridhar KR. 2008 Effect of electron beam irradiation on the quality characteristics of an economically valued tropical legume Mucuna Prurines. Electronic Journal of Environmental, Agricultural and Food Chemistry 7 (12): 2578-2581

Bhattacharee P, Singhal RS, Gholap AS, Variyar PS, Bongirwar DR. 2003 Compositional profiles of $\gamma$-irradiated cashew nuts. Food Chemistry 80:159-163

Centers for Disease Control and Prevention. 2007 Multistate outbreak of Salmonella serotype Tennessee infections associated with peanut butter—United States, 2006-2007 MMWR 56:521525

Centers for Disease Control and Prevention. 2009 Multistate outbreak of Salmonella infections associated with peanut butter and peanut butter—containing products—United States, 2008-2009

Chung S, Yang W, Krishnamurthy K. 2008 Effects of Pulsed UV-light on Peanut Allergies in Extracts and Liquid Peanut Butters. Food Chemistry 73 (5): C400-C404

Gölge E, Ova G. 2008. The effects of food irradiation on quality of pine nut kernels. Radiation Physics and Chemistry 77:365-369

Gornall, A.G., Bardawill, C.J., and David, M.M. 1949. Determination of serum proteins by means of biuret reaction. J. Biol. Chem. 177:751

Huang S, Herald TJ, Mueller DD.1997 Effect of electron beam irradiation on physical, physicochemical, and functional properties of liquid egg yolk during frozen storage. Poultry Science 76:1607-1615

Hvizdzak AL, Beamer S, Jaczynski J, Matak KE. Use of electron beam radiation for the reduction of Salmonella enterica Serovars Typhimurium and Tennessee in Peanut Butter. Journal of Food Protection 73 (2):353-357

Jaczynski J, Park JW. 2004 Physicochemical changes in Alaska Pollock Surimi and Surimi Gel as affected by Electron Beam. Journal of Food Science 69 (1):FCT53-FCT57

Kashani GG, Valadon RG. 1984 Effects of gamma irradiation on the lipids, carbohydrates, and proteins of Iranian pistachio kernels. Journal of Food Technology 19:631-638 
Kang I-H, Gallo M, Tillman BL. 2007 Distribution of Allergen Composition in Peanut (Arachis hypogaea L.) and Wild Progenitor (Arachis) Species. Crop and Soil Science 47 (3):997-1003

Maity JP. 2009 Effects of gamma irradiation on edible seed protein, amino acids and genomic DNA during sterilization. Food Chemistry 114:1237-1244

Matak KE and Jaczynski J.2009. Food Preservation with Electron Beam. Food Science Research and Technology. (pp. 229-245) New York, NY: Nova Science Publishers Inc.

Mexis SF, Badeka AV, Chouliara E, Riganakos KA, Kontominas MG. 2009 Effect of $\gamma$ irradiation on the physicochemical and sensory properties of raw unpeeled almonds kernels (Prunus dulcis). Innovative Food Science and Emerging Technologies 10: 87-92.

Mexis SF, Kontominas MG. 2009 Effect of $\gamma$-irradiation on the physicochemical and sensory properties of hazelnuts. Radiation Physics and Chemistry 78:407-413

Oh S-H, Lee Y-S, Lee J-W, Kim MR, Yook H-S, Byun M-W 2005 The effect of $\gamma$-irradiation on non-enzymatic browning reaction in the aqueous model solution. Food Chemistry 92 (2): 357363

Sánchex-Bel P, Egea I, Romojaro F, Martinez-Madrid C. 2006 Sensorial and chemical quality of electron beam irradiated almonds (Prunus amygdalus). LWT-Food Science and Technology 41: 442-449

Shachar D and Yaron S. 2006. Heat tolerance of Salmonella serovars Agona, Enteritidis, and Typhimumium in peanut butter. Journal of Food Protection 69: 2687-2691

Stewart EM. 2001 Food irradiation Chemistry, Food Irradiation Principles and Applications (pp.37-75) New York, NY: John Wiley \& Sons, Inc.

U.S. Food and Drug Administration. 2009. Food Irradiation Consumer Information. Available at: http://www.fda.gov/Food/FoodIngredientsPackaging/IrradiatedFoodPackaging/ucm135143.htm Accessed 17 May 2010.

Yu TC, Sinnhuber RO. 1957. 2-Thiobarbituric acid method for the measurement of rancidity in fishery products. Food Technology 11: 104-108 
Table 1: Thiobarbituric acid reactive substances test (TBARS) analyzed by dose and by day. Color absorbance was read at $532 \mathrm{~nm}$ and TBARS values were reported as $\mathrm{mg}$ malondialdehyde (MDA) per $\mathrm{kg}$ sample.

\begin{tabular}{llcccc}
\hline \multicolumn{7}{c}{ MDA (mg/kg sample) } & & \\
Day & \multicolumn{1}{c}{$\mathbf{0 ~ k G y ~ ( c o n t r o l ) ~}$} & $\mathbf{3 . 2} \mathbf{~ k G y}$ & $\mathbf{7 ~ k G y}$ & $\mathbf{2 7 . 7} \mathbf{~ k G y}$ & $\mathbf{R}^{2}$ \\
\hline $\mathbf{3}$ & $0.98 \pm 0.12^{\mathrm{Bc}}$ & $1.56 \pm 0.22^{\mathrm{ABb}}$ & $1.75 \pm 0.08^{\mathrm{Ab}}$ & $2.69 \pm 0.35^{\mathrm{ABa}}$ & 0.93 \\
$\mathbf{5}$ & $1.11 \pm 0.00^{\mathrm{ABc}}$ & $1.29 \pm 0.17^{\mathrm{Bc}}$ & $1.82 \pm 0.25^{\mathrm{Ab}}$ & $2.55 \pm 0.14^{\mathrm{ABa}}$ & 0.93 \\
$\mathbf{7}$ & $1.01 \pm 0.30^{\mathrm{Bb}}$ & $1.53 \pm 0.32^{\mathrm{ABab}}$ & $1.53 \pm 0.38^{\mathrm{Aab}}$ & $2.18 \pm 0.19^{\mathrm{Ba}}$ & 0.88 \\
$\mathbf{9}$ & $1.26 \pm 0.33^{\mathrm{ABb}}$ & $1.50 \pm 0.17^{\mathrm{ABb}}$ & $1.72 \pm 0.25^{\mathrm{Aab}}$ & $2.27 \pm 0.12^{\mathrm{Ba}}$ & 0.96 \\
$\mathbf{1 5}$ & $1.61 \pm 0.05^{\mathrm{Ab}}$ & $1.90 \pm 0.23^{\mathrm{Ab}}$ & $1.75 \pm 0.14^{\mathrm{Ab}}$ & $2.91 \pm 0.09^{\mathrm{Aa}}$ & 0.95 \\
\hline
\end{tabular}

${ }^{+}$Values are mean score \pm SD $(n=3)$.

A, B, C Values with designated with different uppercase letters within a column indicate significant differences over time $(P<0.05)$.

${ }^{a b c}$ Values designated with different lowercase letters within the same row indicant significant differences as a function of dose $(P<0.05)$. 
Table 2 Fatty acid analysis of peanut butter treated with different e-beam doses on days-3 and 15 after treatment. No significant differences, as determined by Tukey's honestly significant difference test $(P<0.05)$, between day 3 and 15 were found.

\begin{tabular}{|c|c|c|c|c|c|c|c|c|}
\hline Fatty Acid & & & 3 & & & Da & 15 & \\
\hline Dose (kGy) & 0 (Control) & 3.2 & 7.0 & 27.7 & 0 (Control) & 3.2 & 7.0 & 27.7 \\
\hline$(16: 0)$ & $10.14 \pm 0.13$ & $10.19 \pm 0.11$ & $10.03 \pm 0.12$ & $10.10 \pm 0.12$ & $10.22 \pm 0.04^{\mathrm{a}}$ & $10.04 \pm 0.08^{\mathrm{b}}$ & $10.11 \pm 0.09^{\mathrm{ab}}$ & $10.10 \pm 0.03^{\mathrm{ab}}$ \\
\hline$(17: 0)$ & $0.11 \pm 0.00$ & $0.11 \pm 0.01$ & $0.11 \pm 0.01$ & $0.11 \pm 0.00$ & $0.11 \pm 0.01$ & $0.11 \pm 0.01$ & $0.11 \pm 0.01$ & $0.11 \pm 0.01$ \\
\hline$(18: 0)$ & $4.07 \pm 0.11$ & $4.19 \pm 0.09$ & $4.29 \pm 0.15$ & $4.21 \pm 0.07$ & $4.17 \pm 0.08$ & $4.18+0.09$ & $4.25 \pm 0.11$ & $4.27 \pm 0.26$ \\
\hline$(20: 0)$ & $1.35 \pm 0.01$ & $1.34 \pm 0.00$ & $1.37 \pm 0.03$ & $1.37 \pm 0.01$ & $1.35 \pm 0.02$ & $1.35 \pm 0.01$ & $1.36 \pm 0.02$ & $1.35 \pm 0.02$ \\
\hline$(22: 0)$ & $3.34 \pm 0.05$ & $3.33 \pm 0.09$ & $3.43 \pm 0.06$ & $3.40 \pm 0.08$ & $3.33 \pm 0.06$ & $3.38 \pm 0.04$ & $3.42 \pm 0.04$ & $3.42 \pm 0.13$ \\
\hline$(24: 0)$ & $1.55 \pm 0.05$ & $1.55 \pm 0.04$ & $1.55 \pm 0.03$ & $1.57 \pm 0.04$ & $1.50+0.02^{b}$ & $1.55 \pm 0.01^{\mathrm{ab}}$ & $1.56 \pm 0.02^{\mathrm{ab}}$ & $1.57 \pm 0.04^{\mathrm{a}}$ \\
\hline $\begin{array}{l}\text { Total } \\
\text { Saturated } \\
\text { Fat }\end{array}$ & $20.56 \pm 0.15$ & $20.72 \pm 0.30$ & $20.77 \pm 0.14$ & $20.76 \pm 0.08$ & $20.69 \pm 0.12$ & $20.62 \pm 0.21$ & $20.81 \pm 0.15$ & $20.82 \pm 0.40$ \\
\hline$(16: 1)$ & $0.03 \pm 0.06$ & $0.03 \pm 0.05$ & $0.10 \pm 0.01$ & $0.03 \pm 0.05$ & $0.07 \pm 0.06$ & $0.06 \pm 0.06$ & $0.03 \pm 0.06$ & $0.03 \pm 0.06$ \\
\hline (18:1n9) & $51.60 \pm 0.29$ & $51.57 \pm 0.18$ & $51.58 \pm 0.23$ & $51.60 \pm 0.26$ & $51.42 \pm 0.01$ & $51.73 \pm 0.13$ & $51.58 \pm 0.30$ & $51.61 \pm 0.07$ \\
\hline$(18: 1 t 9)$ & $0.17 \pm 0.02^{b}$ & $0.17 \pm 0.01^{\mathrm{b}}$ & $0.18 \pm 0.02^{\mathrm{ab}}$ & $0.22 \pm 0.02^{\mathrm{a}}$ & $0.20 \pm 0.01^{\mathrm{ab}}$ & $0.17 \pm 0.01^{\mathrm{b}}$ & $0.18 \pm 0.03^{b}$ & $0.23 \pm 0.02^{\mathrm{a}}$ \\
\hline$(18: 2)$ & $25.80 \pm 0.23$ & $25.75 \pm 0.37$ & $25.52 \pm 0.42$ & $25.52 \pm 0.40$ & $25.88 \pm 0.04$ & $25.57 \pm 0.08$ & $25.54+0.29$ & $25.36 \pm 0.48$ \\
\hline$(20: 1 n 9)$ & $1.33 \pm 0.02$ & $1.34 \pm 0.03$ & $1.35 \pm 0.04$ & $1.34 \pm 0.03$ & $1.32 \pm 0.01$ & $1.35 \pm 0.01$ & $1.34 \pm 0.05$ & $1.34 \pm 0.02$ \\
\hline $\begin{array}{c}\text { (22:6 T3; } \\
\text { DHA) }\end{array}$ & $0.24 \pm 0.01$ & $0.25 \pm 0.01$ & $0.24 \pm 0.01$ & $0.24 \pm 0.01$ & $0.24 \pm 0.01$ & $0.24 \pm 0.01$ & $0.24 \pm 0.01$ & $0.25 \pm 0.01$ \\
\hline $\begin{array}{c}\text { Total } \\
\text { Unsaturated } \\
\text { Fat }\end{array}$ & $79.17 \pm 0.15$ & $79.10+0.15$ & $78.96+0.15$ & $78.94+0.17$ & $79.13 \pm 0.10$ & $79.13+0.23$ & $78.92+0.16$ & $78.82+0.39$ \\
\hline $\begin{array}{l}\text { Total Mono- } \\
\text { unsaturated }\end{array}$ & $53.13+0.23$ & $53.11+0.22$ & $53.21+0.27$ & $53.19+0.28$ & $53.01+0.07$ & $53.31+0.16$ & $53.14+0.34$ & $53.21+0.08$ \\
\hline $\begin{array}{l}\text { Total Poly- } \\
\text { unsaturated }\end{array}$ & $26.04+0.22$ & $25.99+0.36$ & $25.75+0.41$ & $25.76+0.40$ & $26.12+0.04$ & $25.82+0.07$ & $25.78+0.29$ & $25.61+0.47$ \\
\hline
\end{tabular}

${ }^{+}$Values are given as g / $100 \mathrm{~g}$ lipid. Data are given as mean scores \pm SD $(n=3)$ for each treatment for each analysis

${ }^{\mathrm{a}, \mathrm{b}}$ Values designated with different letters with in the same row for the same day are significantly different $(P<0.05)$ as determined by Tukey’s honestly significant difference test. 
Table 3: Amino acid analysis of peanut butter at treated with different e-beam doses at day 15.

\begin{tabular}{|c|c|c|c|c|}
\hline & \multicolumn{4}{|c|}{ E-beam Dose } \\
\hline & 0 kGy & $3.2 \mathrm{kGy}$ & 7.0 kGy & 27.7 kGy \\
\hline Crude Protein & $25.04 \pm 0.22$ & $24.34 \pm 0.50$ & $24.69 \pm 0.81$ & $25.02 \pm 0.38$ \\
\hline Total Protein & $24.33 \pm 0.48$ & $23.29 \pm 0.23$ & $24.05 \pm 0.62$ & $24.47 \pm 0.50$ \\
\hline Taurine & $0.02 \pm 0.01$ & $0.01 \pm 0.00$ & $0.01 \pm 0.00$ & $0.01 \pm 0.00$ \\
\hline Hydroxyproline & $0.16 \pm 0.08$ & $0.15 \pm 0.07$ & $0.15 \pm 0.08$ & $0.15 \pm 0.08$ \\
\hline Aspartic Acid & $2.93 \pm 0.10$ & $2.86 \pm 0.02$ & $2.96 \pm 0.08$ & $2.87 \pm 0.06$ \\
\hline Threonine & $0.63 \pm 0.02$ & $0.65 \pm 0.02$ & $0.64 \pm 0.02$ & $0.62 \pm 0.01$ \\
\hline Serine & $1.09 \pm 0.03^{\mathrm{a}}$ & $0.99 \pm 0.02^{b}$ & $1.02 \pm 0.02^{b}$ & $1.01 \pm 0.04^{b}$ \\
\hline Glutamic Acid & $4.68 \pm 0.09$ & $4.48 \pm 0.03$ & $4.65 \pm 0.14$ & $4.52 \pm 0.10$ \\
\hline Proline & $1.01 \pm 0.02$ & $0.97 \pm 0.01$ & $0.99 \pm 0.04$ & $0.96 \pm 0.03$ \\
\hline Lanthionine & $0.11 \pm 0.02$ & $0.15 \pm 0.01$ & $0.13 \pm 0.03$ & $0.15 \pm 0.03$ \\
\hline Glycine & $1.48 \pm 0.03$ & $1.42 \pm 0.02$ & $1.46 \pm 0.05$ & $1.44 \pm 0.05$ \\
\hline Alanine & $0.98 \pm 0.02$ & $0.94 \pm 0.01$ & $0.97 \pm 0.03$ & $0.95 \pm 0.03$ \\
\hline Cysteine & $0.31 \pm 0.00$ & $0.30 \pm 0.01$ & $0.30 \pm 0.02$ & $0.32 \pm 0.03$ \\
\hline Valine & $1.08 \pm 0.02$ & $1.06 \pm 0.01$ & $1.10 \pm 0.04$ & $1.07 \pm 0.03$ \\
\hline Methionine & $0.24 \pm 0.01$ & $0.24 \pm 0.01$ & $0.24 \pm 0.01$ & $0.24 \pm 0.01$ \\
\hline Isoleucine & $0.91 \pm 0.02$ & $0.89 \pm 0.01$ & $0.93 \pm 0.03$ & $0.90 \pm 0.03$ \\
\hline Leucine & $1.69 \pm 0.02$ & $1.62 \pm 0.01$ & $1.68 \pm 0.03$ & $1.64 \pm 0.02$ \\
\hline Tyrosine & $0.99 \pm 0.02^{\mathrm{a}}$ & $0.90 \pm 0.05^{\mathrm{ab}}$ & $0.93 \pm 0.02^{b}$ & $0.90 \pm 0.02^{b}$ \\
\hline Phenylalanine & $1.30 \pm 0.03$ & $1.24 \pm 0.01$ & $1.29 \pm 0.04$ & $1.26 \pm 0.03$ \\
\hline Ornithine & $0.01 \pm 0.01$ & $0.02 \pm 0.00$ & $0.02 \pm 0.00$ & $0.02 \pm 0.00$ \\
\hline Lysine & $0.81 \pm 0.02$ & $0.77 \pm 0.01$ & $0.79 \pm 0.01$ & $0.77 \pm 0.02$ \\
\hline Histidine & $0.63 \pm 0.02^{\mathrm{a}}$ & $0.60 \pm 0.00^{b}$ & $0.61 \pm 0.02^{\mathrm{ab}}$ & $0.60 \pm 0.01^{\mathrm{ab}}$ \\
\hline Arginine & $2.91 \pm 0.05^{\mathrm{a}}$ & $2.78 \pm 0.03^{b}$ & $2.88 \pm 0.08^{\mathrm{ab}}$ & $2.80 \pm 0.04^{\mathrm{ab}}$ \\
\hline Tryptophan & $0.29 \pm 0.02$ & $0.29 \pm 0.01$ & $0.27 \pm 0.01$ & $0.26 \pm 0.01$ \\
\hline $\begin{array}{l}{ }^{+} \text {Values are give } \\
\text { treatment for e } \\
\text { a, b Values desigı } \\
(P<0.05) \text { as }\end{array}$ & $\begin{array}{l}\text { g / } 100 \text { g san } \\
\text { analysis } \\
\text { with differe } \\
\text { mined by Tu }\end{array}$ & s with in the & $\begin{array}{l}\text { W are signific } \\
\text { ifference test. }\end{array}$ & $\begin{array}{l}\text { for each } \\
\text { different }\end{array}$ \\
\hline
\end{tabular}


Table 4: Pixel density, Average Value of Pixel Ratio is equal to the number of pixels in a given area divided by that given area, as shown by Sodium dodecyl sulfate polyacrylamide gel electrophoresis (SDS-Page). Pixel density was determined by Flurochem ${ }^{T M} 8000$ Advanced Fluorescence, Chemiluminescence \& Visible Light Imaging. All treatments were done in triplicate.

Average Value of Pixel Ratio

\begin{tabular}{|c|c|c|c|c|}
\hline \multirow[b]{2}{*}{ Protein Band } & \\
\hline & 0 kGy* & $3.2 \mathrm{kGy}^{++}$ & $7.0 \mathrm{kGy}^{++}$ & 27.7 kGy* \\
\hline A & $0.62 \pm 0.04^{\mathrm{a}}$ & $0.73 \pm 0.08^{\mathrm{a}}$ & $0.68 \pm 0.03^{\mathrm{a}}$ & $0.30 \pm 0.04^{b}$ \\
\hline $\mathrm{B}$ & $0.88 \pm 0.02^{\mathrm{a}}$ & $0.88 \pm 0.09^{\mathrm{a}}$ & $0.83 \pm 0.11^{\mathrm{a}}$ & $0.45 \pm 0.02^{b}$ \\
\hline $\mathrm{C}$ & $0.85 \pm 0.11^{\mathrm{a}}$ & $0.77 \pm 0.04^{\mathrm{a}}$ & $0.71 \pm 0.7^{\mathrm{a}}$ & $0.46 \pm 0.03^{b}$ \\
\hline $\mathrm{D}$ & $0.49 \pm 0.05^{\mathrm{a}}$ & $0.49 \pm 0.02^{\mathrm{a}}$ & $0.46 \pm 0.06^{\mathrm{a}}$ & $0.39 \pm 0.04^{\mathrm{a}}$ \\
\hline $\mathrm{E}$ & $0.37 \pm 0.08^{a}$ & $0.26 \pm 0.01^{\mathrm{a}}$ & $0.68 \pm 0.33^{\mathrm{a}}$ & $0.31 \pm 0.01^{\mathrm{a}}$ \\
\hline \multicolumn{5}{|c|}{$\begin{array}{l}{ }^{+} \text {Data are given as mean scores }+ \text { SD } \\
+n=3 \\
* n=7\end{array}$} \\
\hline
\end{tabular}


Table 5a and 5b: Texture analysis of e-beamed peanut butter using a texture analyzer fitted with a cone-shaped probe. Force 1(Table 5a) represents the amount of force exerted as probe penetrates peanut butter. Force 2 (Table $5 b$ ) represents the amount of force as probe exits the penetrated peanut butter.

Table 5a. Force 1

\begin{tabular}{lllll}
\hline Day & 0 kGy (control) & $\mathbf{3 . 2}$ kGy & $\mathbf{7 . 0} \mathbf{~ k G y}$ & $\mathbf{2 7 . 7} \mathbf{~ k G y}$ \\
\hline $\mathbf{3}$ & $3046.08 \pm 245.66^{\mathrm{B}}$ & $3148.22 \pm 208.29^{\mathrm{B}}$ & $3084.11 \pm 146.30^{\mathrm{B}}$ & $2877.49 \pm 337.86^{\mathrm{B}}$ \\
$\mathbf{5}$ & $4496.03 \pm 168.70^{\mathrm{A}}$ & $4935.59 \pm 1003.30^{\mathrm{A}}$ & $4413.07 \pm 186.21^{\mathrm{A}}$ & $4224.65 \pm 584.39^{\mathrm{A}}$ \\
$\mathbf{7}$ & $1944.61 \pm 251.55^{\mathrm{D}}$ & $1754.66 \pm 150.99^{\mathrm{C}}$ & $1868.18 \pm 225.64^{\mathrm{C}}$ & $1792.98 \pm 227.36^{\mathrm{C}}$ \\
$\mathbf{9}$ & $2793.99 \pm 218.35^{\mathrm{BCa}}$ & $2306.71 \pm 175.12^{\mathrm{BCab}}$ & $1978.32 \pm 223.36^{\mathrm{Cb}}$ & $2213.94 \pm 229.51^{\mathrm{BCb}}$ \\
$\mathbf{1 5}$ & $2202.56 \pm 274.97^{\mathrm{CDa}}$ & $1670.25 \pm 130.07^{\mathrm{Cab}}$ & $1662.99 \pm 318.03^{\mathrm{Cab}}$ & $1589.90 \pm 69.04^{\mathrm{Cb}}$ \\
\hline
\end{tabular}

Table $5 b$. Force 2

\begin{tabular}{lllll}
\hline Day & 0 kGy (control) & 3.2 kGy & $\mathbf{7 . 0}$ kGy & $\mathbf{2 7 . 7}$ kGy \\
\hline $\mathbf{3}$ & $-4230.8 \pm 307.97^{\mathrm{B}}$ & $-4193.6 \pm 760.52^{\mathrm{B}}$ & $-4611.4 \pm 305.92^{\mathrm{B}}$ & $-4516.4 \pm 410.28^{\mathrm{BC}}$ \\
$\mathbf{5}$ & $-6184.7 \pm 385.93^{\mathrm{C}}$ & $-6781.9 \pm 726.31^{\mathrm{C}}$ & $-6304.1 \pm 363.19^{\mathrm{C}}$ & $-5861.8 \pm 1062.08^{\mathrm{C}}$ \\
$\mathbf{7}$ & $-2779.6 \pm 352.62^{\mathrm{A}}$ & $-2490.9 \pm 216.64^{\mathrm{A}}$ & $-2708.0 \pm 341.84^{\mathrm{A}}$ & $-2584.1 \pm 267.36^{\mathrm{A}}$ \\
$\mathbf{9}$ & $-4397.3 \pm 206.36^{\mathrm{Bb}}$ & $-3633.1 \pm 103.34^{\mathrm{ABa}}$ & $-3052.1 \pm 268.01^{\mathrm{Aa}}$ & $-3390.6 \pm 269.31^{\mathrm{ABa}}$ \\
$\mathbf{1 5}$ & $-3251.0 \pm 350.139^{\mathrm{A}}$ & $-2554.0 \pm 189.33^{\mathrm{A}}$ & $-2503.4 \pm 423.71^{\mathrm{A}}$ & $-2501.1 \pm 73.50^{\mathrm{A}}$ \\
\hline
\end{tabular}

${ }^{+}$Values are mean score \pm SD $(n=3)$.

A, B, C, D Values designated with different letters within the same treatment and same column are significantly different $(P<0.05)$ as determined by Tukey's honestly significant difference test.

${ }^{\mathrm{a}, \mathrm{b}}$ Values designated with different letters with in the same row are significantly different $(P<$ 0.05 ) as determined by Tukey's honestly significant difference test. 
Table 6a, 6b, 6c: Color analysis of e-beamed peanut butter. Table 6a represents L-value (lightness). Table $6 b$ represents $a^{*}$ value (redness). Table $6 c$ represents $b^{*}$ value (yellowness).

Table a. L-value (lightness)

\begin{tabular}{lllll}
\hline Day & 0 kGy (control) & $\mathbf{3 . 2} \mathbf{~ k G}$ & $\mathbf{7 . 0} \mathbf{~ k G y}$ & $\mathbf{2 7 . 7} \mathbf{~ k G y}$ \\
\hline $\mathbf{3}$ & $57.56 \pm 1.03^{\mathrm{a}}$ & $57.95 \pm 0.10^{\mathrm{ABa}}$ & $55.38 \pm 0.78^{\mathrm{a}}$ & $52.65 \pm 1.51^{\mathrm{Bb}}$ \\
$\mathbf{5}$ & $58.27 \pm 0.27^{\mathrm{a}}$ & $57.11 \pm 0.14^{\mathrm{Ba}}$ & $54.78 \pm 1.02^{\mathrm{b}}$ & $54.34 \pm 0.32^{\mathrm{ABb}}$ \\
$\mathbf{7}$ & $57.65 \pm 1.11^{\mathrm{a}}$ & $57.90 \pm 0.58^{\mathrm{ABa}}$ & $54.80 \pm 0.43^{\mathrm{b}}$ & $54.87 \pm 0.33^{\mathrm{Ab}}$ \\
$\mathbf{9}$ & $58.86 \pm 0.70^{\mathrm{a}}$ & $57.56 \pm 0.44^{\mathrm{Bb}}$ & $54.81 \pm 0.17^{\mathrm{C}}$ & $55.06 \pm 0.26^{\mathrm{Ac}}$ \\
$\mathbf{1 5}$ & $58.96 \pm 0.20^{\mathrm{a}}$ & $58.96 \pm 0.44^{\mathrm{Aa}}$ & $54.85 \pm 0.23^{\mathrm{b}}$ & $55.89 \pm 0.67^{\mathrm{Ab}}$ \\
\hline
\end{tabular}

Table b. $a^{*}$ value (redness)

\begin{tabular}{lllll}
\hline Day & 0 kGy (control) & 3.2 kGy & $\mathbf{7 . 0 ~ k G y ~}$ & $\mathbf{2 7 . 7} \mathbf{~ k G y}$ \\
\hline $\mathbf{3}$ & $11.22 \pm 0.29^{\mathrm{a}}$ & $10.46 \pm 0.07^{\mathrm{Ab}}$ & $10.60 \pm 0.15^{\mathrm{b}}$ & $10.22 \pm 0.31^{\mathrm{b}}$ \\
$\mathbf{5}$ & $11.00 \pm 0.12^{\mathrm{a}}$ & $10.55 \pm 0.09^{\mathrm{ABa}}$ & $10.75 \pm 0.20^{\mathrm{a}}$ & $9.83 \pm 0.40^{\mathrm{b}}$ \\
$\mathbf{7}$ & $11.06 \pm 0.24^{\mathrm{a}}$ & $10.20 \pm 0.05^{\mathrm{ABb}}$ & $10.63 \pm 0.18^{\mathrm{C}}$ & $10.01 \pm 0.02^{\mathrm{C}}$ \\
$\mathbf{9}$ & $10.35 \pm 0.96$ & $10.39 \pm 0.18^{\mathrm{AB}}$ & $10.68 \pm 0.05$ & $10.05 \pm 0.12$ \\
$\mathbf{1 5}$ & $10.77 \pm 0.13^{\mathrm{a}}$ & $10.17 \pm 0.21^{\mathrm{Bb}}$ & $10.98 \pm 0.06^{\mathrm{a}}$ & $10.14 \pm 0.05^{\mathrm{b}}$ \\
\hline
\end{tabular}

Table c. $b^{*}$ value (yellowness)

\begin{tabular}{lllll}
\hline Day & 0 kGy (control) & $\mathbf{3 . 2}$ kGy & $\mathbf{7 . 0}$ kGy & $\mathbf{2 7 . 7} \mathbf{~ k G y}$ \\
\hline $\mathbf{3}$ & $29.50 \pm 0.80^{\mathrm{a}}$ & $28.80 \pm 0.23^{\mathrm{ABa}}$ & $25.66 \pm 0.63^{\mathrm{Bb}}$ & $25.64 \pm 0.91^{\mathrm{b}}$ \\
$\mathbf{5}$ & $28.64 \pm 0.17$ & $28.63 \pm 0.17^{\mathrm{AB}}$ & $26.62 \pm 1.63^{\mathrm{B}}$ & $26.76 \pm 0.57$ \\
$\mathbf{7}$ & $29.68 \pm 0.80^{\mathrm{a}}$ & $28.90 \pm 0.29^{\mathrm{Aa}}$ & $26.57 \pm 0.62^{\mathrm{Bb}}$ & $26.10 \pm 0.13^{\mathrm{b}}$ \\
$\mathbf{9}$ & $29.45 \pm 0.13^{\mathrm{a}}$ & $28.35 \pm 0.06^{\mathrm{Bb}}$ & $27.09 \pm 0.08^{\mathrm{ABC}}$ & $26.22 \pm 0.40^{\mathrm{d}}$ \\
$\mathbf{1 5}$ & $29.65 \pm 0.06^{\mathrm{a}}$ & $28.89 \pm 0.09^{\mathrm{Aa}}$ & $29.30 \pm 0.46^{\mathrm{Aa}}$ & $27.27 \pm 0.73^{\mathrm{b}}$ \\
\hline
\end{tabular}

${ }^{+}$Values are mean score \pm SD $(n=3)$.

${ }^{\mathrm{A}, \mathrm{B}}$ Values designated with different letters within the same treatment and same column are significantly different $(P<0.05)$ as determined by Tukey's honestly significant difference test.

a, b, c Values designated with different letters with in the same row are significantly different $(P<$ 0.05 ) as determined by Tukey's honestly significant difference test. 
Figure 1: Texture Technologies TA-425 TTC Spreadability Fixture ${ }^{T M}$. a) Male probe b) female probe c) peanut butter.
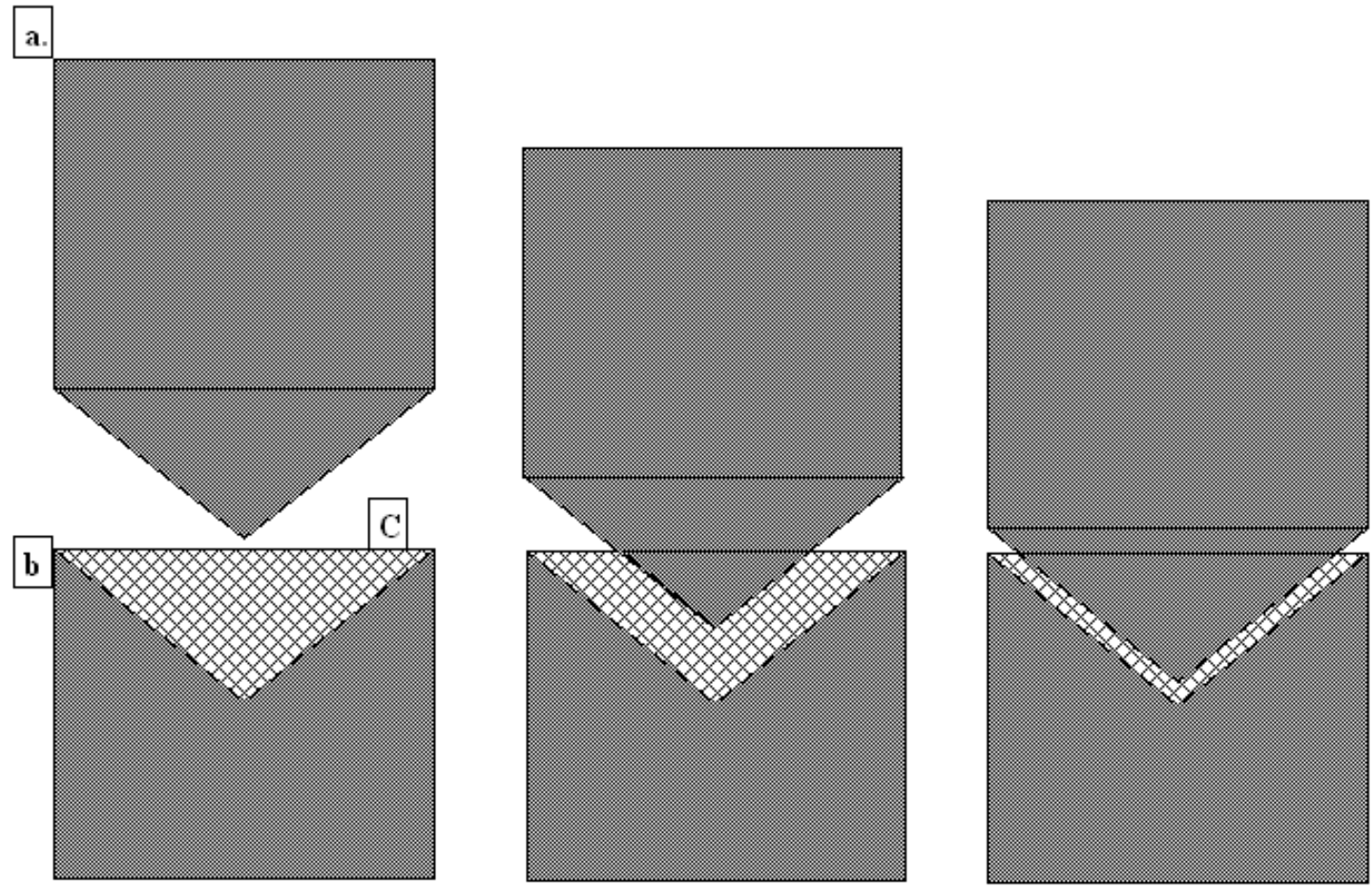
Figure 2: Linear regression of $\mathrm{mg} M D A / \mathrm{kg}$ sample, expressed as a function of dose. Values are equal to the mean of 3 observations $(n=3)$.

\section{MDA formation}

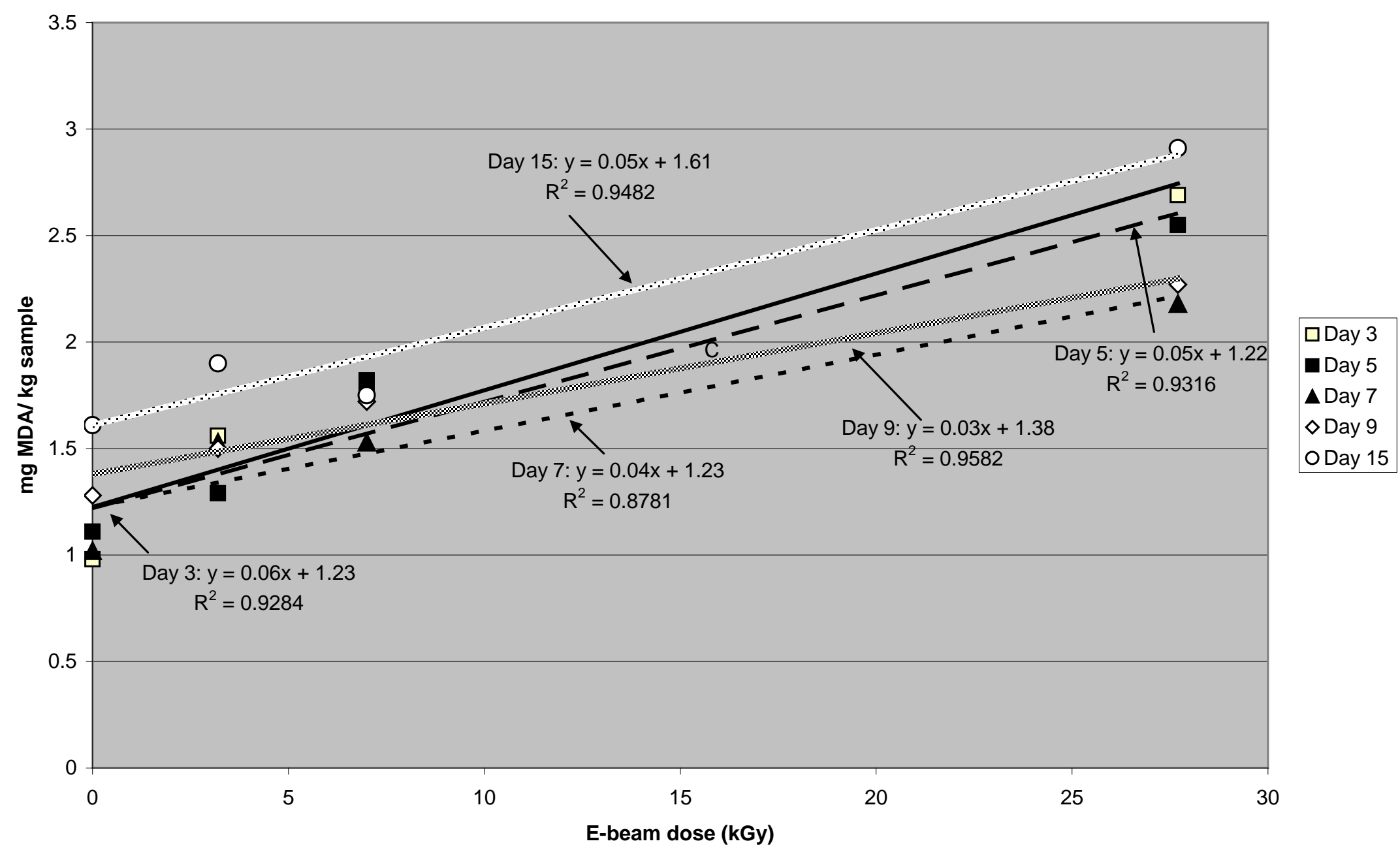


Figure 3: Linear regression of $L^{*}$-value (lightness), expressed as a function of dose. Values are equal to the mean of 3 observations $(n=3)$.

\section{$L^{*}$-Value (Lightness)}

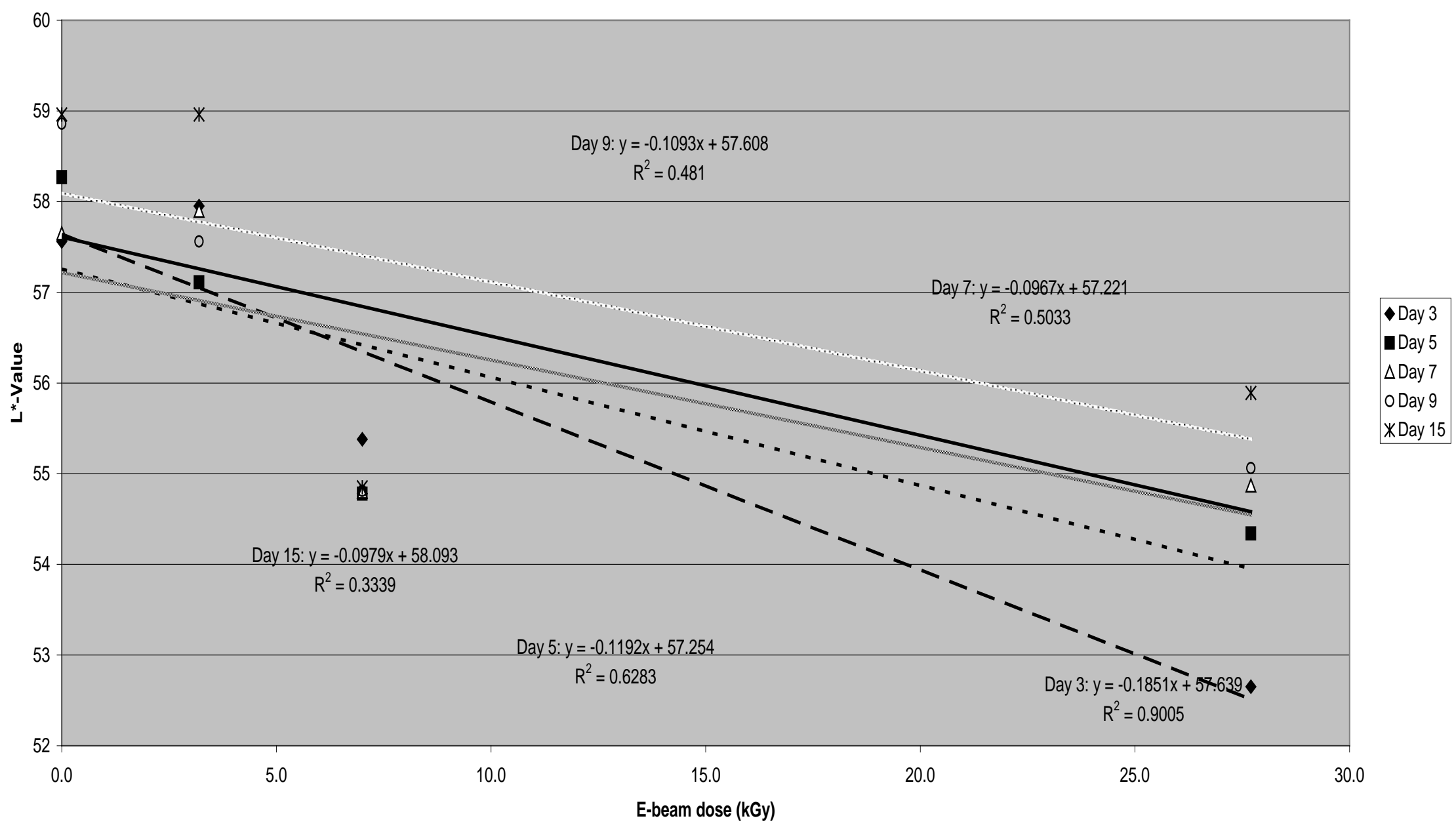




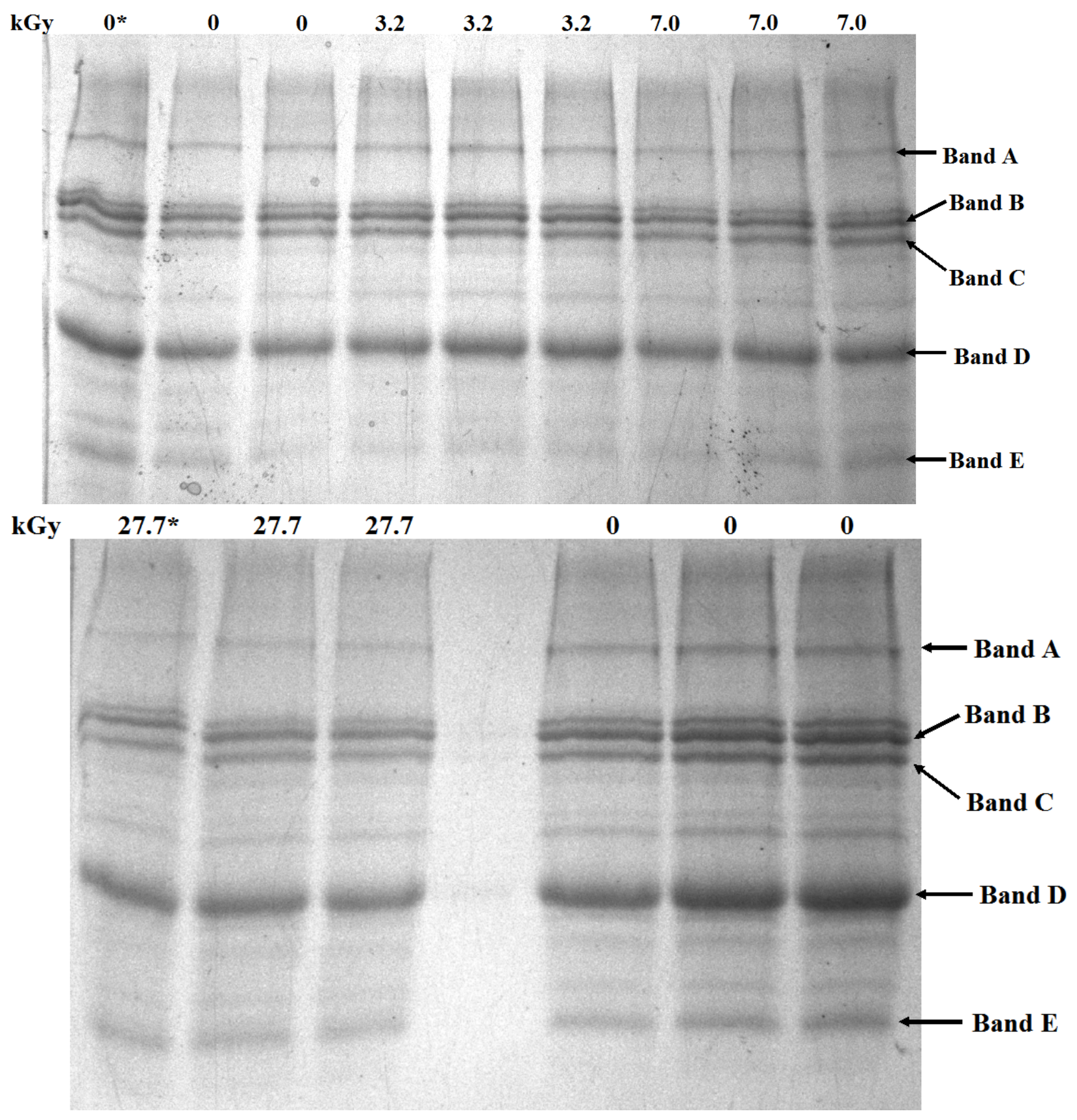

Figure 4:Sodium dodecyl sulfate-polyacrylamide gel electrophoreseis of $45.45 \mu \mathrm{g}$ of peanut butter protein exposed to 0, 3.1, and $7 \mathrm{kGy}$ (top) and 27.7 and $0 \mathrm{kGy}$ bottom on $15 \% \mathrm{Tris}-\mathrm{HCl}$ separating gels.

* Unable obtain accurate pixel density. 


\begin{abstract}
APPENDEX A
Peroxide Value

Peroxide value assay had also been planned as a second measure of lipid oxidation; however during pre-study testing, the assay failed to be completed correctly after it had been tried several times on peanut butter and corn oil. Approximately $5 \mathrm{~g}$ of peanut butter was dissolved in $30 \mathrm{~mL}$ of 3 parts acetic acid and 2 parts chloroform. $0.5 \mathrm{~mL}$ of saturated potassium iodide was added and let stand for one minute. $30 \mathrm{~mL}$ of water was added to the solution and gentle mixed. Iodine solution was then slowly titrated with a standard solution of sodium thiosulfate until the pale yellow color of the mixture was nearly gone. $0.5 \mathrm{~mL}$ of starch solution (S516 Fisher Chemicals) was then added. Solution was supposed to turn blue and then titration was to be continued, however the solution never turned blue. Procedure was done using different types of starches and was not successful.
\end{abstract}

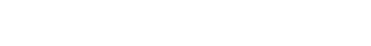

